\title{
GROUND VIBRATION TEST PLANNING AND PRE-TEST ANALYSIS FOR THE X-33 VEHICLE
}

\author{
Herand Bedrossian * \\ Lockheed Martin Skunk Works \\ 1011 Lockheed Way \\ Palmdale, CA 93599-2545
}

\author{
Michael L. Tinker ${ }^{\star \star}$ and Homero Hidalgo + \\ Structural Dynamics and Loads Group/ED21 \\ Structures, Mechanics, and Thermal Department \\ NASAMarshall Space Flight Center \\ Huntsville, AL 35812
}

\section{Abstract}

This paper describes the results of the modal test planning and the pre-test analysis for the $\mathrm{X}-33$ vehicle. The pre-test analysis included the selection of the target modes, selection of the sensor and shaker locations and the development of an accurate Test Analysis Model (TAM). For target mode selection, four techniques were considered; one based on the Modal Cost technique, one based on Balanced Singular Value technique, a technique known as the Root Sum Squared (RSS) method, and a Modal Kinetic Energy (MKE) approach. For selecting sensor locations, four techniques were also considered; one based on the Weighted Average Kinetic Energy (WAKE), one based on Guyan Reduction (GR), one emphasizing engineering judgment, and one based on an optimum sensor selection technique using Genetic Algorithm (GA) search technique combined with a criteria based on Hankel Singular Values (HSV's). For selecting shaker locations, four techniques were also considered; one based on the Weighted Average Driving Point Residue (WADPR), one based on engineering judgment and accessibility considerations, a frequency response method, and an optimum shaker location selection based on a GA search technique combined with a criteria based on HSV's.

To evaluate the effectiveness of the proposed sensor and shaker locations for exciting the target modes, extensive numerical simulations were performed. Multivariate Mode Indicator Function (MMIF) was used to evaluate the effectiveness of each sensor \& shaker set with respect to modal parameter identification. Several TAM reduction techniques were considered including, Guyan, IRS, Modal, and Hybrid. Based on a pre-test cross-orthogonality checks using various reduction techniques, a Hybrid TAM reduction

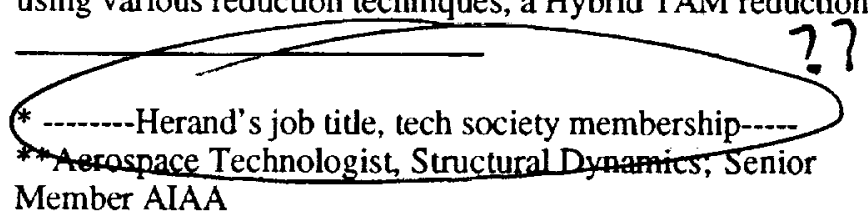

†Aerospace Technologist, Structural Dynamics

Copyright $\Theta 2000$ by the American Institute of Aeronautics and Astronautics, Inc. No copyright is asserted in the United States under Title 17, U.S. Code. The U.S. government has a royalty-free license to exercise all rights under the copyright claimed herein for Governmental purposes. All other rights are reserved by the copyright owner. technique was selected and was used for all three vehicle fuel level configurations.

\section{Introduction}

The $\mathrm{X}-33$ is an advanced technology demonstrator vehicle for the Reusable Launch Vehicle (RLV) program (Fig. 1). Due to cost and schedule issues, the real X-33 flight vehicle will be used during the vehicle Ground Vibration Test (GVT) or modal survey test. The X-33 vehicle will be mounted on a soft airbag isolation system and positioned vertically to simulate the free flight condition, as shown in Fig. 2. Objectives of the GVT include the following:

1. Measure vehicle primary modes, frequencies, and damping for three flight configurations: empty, partially-fueled, and fully-fueled; required for control and liftoff loads.

2. Identify modes of aerodynamic surfaces for flutter.

3. Verify pogo modes and measure damping.

4. Obtain transfer functions from the engine and control surfaces to the Guidance and Pointing System/Inertial Navigation System (GPS/INS) sensor locations for vehicle control.

5. Identify control surface nonlinearities for flutter.

6. Validate thermal protection system (TPS) dynamics.

7. Update the vehicle finite element model (FEM) using measured frequencies and mode shapes.

8. Use test-verified FEM to reassess flight loads, pogo, flutter, and flight control stability margins before first flight to insure safety.

In relation to these objectives and additional goals of characterizing/verifying the launch facility hardware and airbag isolation system, a total of 8 test configurations have been selected for the GVT. These include (a) two component tests for the avionics bay and INS substructure, (b) two vehicle mass simulator tests, in launch and GVT configurations, and (c) four X-33 vehicle tests (empty, partial fuel, full fuel, and TPS dynamics). The X-33 vehicle mass simulator (known as "Iron Bird") is shown mounted at the launch facility in Fig. 3.

A number of objectives were also identified for pre-test analysis of the $\mathrm{X}-33$ vehicle. These included determination of target modes (primary and secondary), accelerometer and 
shaker locations, impact of various mass simulators on vehicle system modes, and impact of the suspension system regarding coupling with vehicle modes. In addition, it was required to develop accurate roduced Test Analysis Models (TAMs) for each vehicle contiguration, and to conduct simulations to verify the adequacy of sensor and shaker locations.

For large complex and built-up structures such as X-33, a large number of sensors and shakers are typically used in order to validate the finite element model (FEM). The FEM with and without the thermal protection system (TPS) visible is shown in Fig. 4. Due to cost, installation or removal, and accessibility issues, only a limited number of sensors and shakers are generally available for placement. It is important that sensors and shakers be optimally placed in order to accurately measure the frequencies and mode shapes of the test article and validate the FEM. The validated FEM can be used for predicting vehicle loads, dynamic response, and the flutter margins.

\section{Target Mode Selection}

The first step in selecting target modes was to determine the frequency ranges of interest for the different disciplines and requirements. Requirements were discussed in the previous section, in regard to objectives for the GVT. Table 1 lists the various requirements in the test objectives, along with the frequency ranges for primary and secondary modes. Frequency ranges were identified from inspection of modes predicted by the model (to determine the nature of the modes) and from consideration of the needs in each discipline or requirement area.

Most of the difficulty encountered in target mode selection was due to the nature of the X-33 structure and the finite element model. The model had approximately 900 modes in the frequency band $0-55 \mathrm{~Hz}$ for each configuration, making visual inspection impossible except as a means of verifying analytical mode selection results. Many or most of these modes were local modes of the TPS and support structure, fuel tank surfaces, fuel lines, various lumped masses, and other items. Analytical approaches were required to sort through the hundreds of modes and identify potential modes of interest. The general approach taken was to use several such tools to drastically reduce the number of modes being considered, and then to verify through visual inspection which modes were indeed target modes.

In general, the analytical methods discussed in this section locate and rank modes having the highest energy or overall largest displacement when considering all degrees-offreedom (DOF) or a strategic group of DOF in the model. This approach is not fail-safe because some local modes have high energy but are still not target modes. Visual inspection is then required for the highest-energy modes to determine if they meet the criteria for target modes, i.e., that they be global vehicle modes, aerosurface modes, or modes of interest to pogo, for example.

\section{Boot-Sum-Square Displacement Method}

A mode shape is defined by the ratio of the amplitudes of motion at the various points on the structure when excited at its natural frequency. If one of the elements of the eigenvector is assigned a certain value, the rest of the elements are also fixed because the ratio between any two elements is constant. The Root-Sum-Square (RSS) method takes advantage of this fact. Otrhonormal modes are used in the RSS method. Normalization to a unit value of the largest eigenvector displacement is applied to the entire model (all the DOF) for all the modes.

Direct comparison between modes for a given vehicle fuel fill condition and for a particular location be done, as well as comparison between modes from different fuel fill conditions (flight configurations) for a particular location. Modes of interest can be identified by visually noting the degree of modal displacement or deformation at a certain location on the structure. For example, noting the vehicle modes in which the canted fin actually distorts identifies canted fin modes. The RSS computes the magnitude of resultant modal displacement values for each mode at selected degrees of freedom (DOF) and sorts to locate modes with highest values. This is expressed in Eq. (1),

\{RSS Resultant Value $\}_{j}=\sum\left[\phi_{x}^{2}+\phi_{y}^{2}+\phi_{z}^{2}\right]^{1 / 2}$

where

1. $\{R S S\}_{j}$ is the summation magnitude value for mode $j$

2 . $\phi$ 's are the eigenvector translation coefficients for mode $\mathrm{j}$ for the selected nodes of interest

The modes with the highest RSS displacement values have the highest overall motion and energy for that particular location or set of nodes. For the canted fin example, several hard points could be chosen along the span and chord and spaced such that expected mode shapes are reasonably covered. Then keying on the RSS displacement values of these nodes, and considering all fuel-level conditions, literally thousands of non-interesting modes are easily and effectively filtered out, leaving only modes of interest. It has been shown that four points can pick up the canted fin modes from the thousands of X-33 FEM vehicle modes. As for vehicle target modes, it has been shown that 86 nodes (out of 22,000 FEM nodes) can identify all the vehicle modes within a $0-25 \mathrm{~Hz}$ band. Above this range for the model, all target modes were aero-control surface modes, which were determined individually.

Additionally, the RSS software sums the absolute modal displacement in the three axis directions for each mode,

$R_{x j}=\Sigma\left|\phi_{x}\right|, R_{y j}=\Sigma\left|\phi_{y}\right|, R_{z j}=\Sigma\left|\phi_{z}\right|$

where $R_{j}$ is the absolute summation value for mode $j$ in the $\mathrm{x}, \mathrm{y}$, and $\mathrm{z}$ component directions. Again, the RSS routine sorts to locate modes with highest values. This yields insight into the directional modal dynamic behavior of the modes. For example, longitudinal or pogo modes were identified in this fashion by looking at modes with the highest $R_{x}$ summation values. In the canted fin example, the directional summation $\left(R_{x}, R_{y}\right.$, and $\left.R_{z}\right)$ values would 
give insight as 10 which bending mode was being identified by resultant RSS displacement value.

In the next section, the modal kinetic energy approach is describud, and RSS results will be shown in comparison to target modes identified by that technique. Both approaches allow a determination of modes having highest energy or overall displacement for all DOF in the model or a set of DOF, and it is instructive to look at the results together.

\section{Modal Kinetic Energy (Generalized Mass) Approach}

This straightforward method is based on calculations of generalized mass on a mode-by-mode basis, which provides a measure of the kinetic energy of all the DOF in the model for a given mode shape. However, the mode shapes must be normalized to maximum displacement to obtain meaningful information from the calculations. As shown in $\mathrm{Eq}$. (3), the modal kinetic energy is given by the diagonals of the generalized mass,

$$
[\mathrm{KE}]=\operatorname{diag}\left[\Phi^{\mathrm{T}} \mathbf{M} \Phi\right]
$$

In this expression, $\Phi$ is the matrix of free-free modes (vehicle on suspension system), and $\mathbf{M}$ is the mass matrix. Comparison and ranking of these diagonal values provides a means of determining which modes have the most energy actoss all the DOF in the model, and are thus candidate target modes.

The modal kinetic energy (MKE) approach when compared to, and used with, the RSS method provides a very powerful approach for filtering out weak or localized modes and identifying potential target modes, These two approaches achieve similar results in that high-energy modes are located. However, the difference in the methods is that the MKE approach uses all the model DOF, while RSS is normally used with a strategic set of points ("control" points) covering all regions of interest on the structure. The implications of this are that MKE will often "flag" highenergy modes where many parts of the structure are moving, but the the modes are not of interest for model correlation. In contrast, the RSS approach allows the analyst to filter out such high-energy non-interesting modes by a proper choice of control points. The two methods taken together are extremely powerful and thorough, for several reasons:

1. The MKE approach rarely misses a potential target mode, but often finds non-interesting modes. However, the analysis must be careful in choosing the threshold value of kinetic energy.

2. The RSS approach does not flag non-interesting highenergy modes, and helps in determining if modes flagged by MKE are truly global modes (or modes involving regions of interest if localized).

3. The MKE approach provides insurance when using RSS, in the event that selected control points for RSS are missing an important region of the structure.

Results for the MKE and RSS methods are presented together for the reasons discussed here. When the top-ranked modes from both MKE and RSS are taken together, and then examined visually for verification, the analyst can have high confidence that the strongest mexdes of interest have been located. Table 2 shows the results for the RSS method, and Table 3 contains the MKE or generalized mass results, both for the empty vehicle case. In both tables, double asterisks (**) indicale very strong modes relative to the minimum value threshold, and single asterisks $\left(^{*}\right)$ indicate modes that are weaker but should still be considered as candidate targets.

\section{Modal Cost Technique} paper.)

(Results for this technique will be provided in the full

\section{Balanced Singular Value Technique}

(Results for this technique will be provided in the full paper.)

Final Determination of Target Modes for the Three Vehicle Configurations

The methodology by which final decisions were made in identifying target modes for each vehicle configuration are as follows:

1. Empty vehicle: Modes were ranked using both the RSS and MKE methods, then examined visually to determine which highly-ranked modes were truly of interest for the GVT objectives.

2. Fully-fueled vehicle: Modes were ranked using RSS, Modal Cost, and Balanced Singular Value approaches. Then a composite list of highest-ranked modes from all three techniques was formed. Visual inspection was used to determine/verify modes of interest for GVT.

3. Partially-fueled vehicle: Modes were ranked using RSS and MKE, and examined visually for verification. Comparison was also made with the empty and fully-fueled cases for further verification, to establish consistency among the cases, and to aid in deciding which partial-fueled modes to retain.

Table 4 shows the composite list of target modes for all three vehicle fuel-level configurations. Many strong global modes and other modes of interest can be found in all three configurations, but some modes can also be seen that are unique for a given configuration. Figure 5 shows several important target modes for the vehicle empty configuration, which were determined using the procedures described in this section.

The target mode selection approach described here worked very well. However, in some cases it was quite difficult to decide when a mode should be eliminated. Some modes had high kinetic energy, and were global in nature, but very highly coupled with localized motion. Such modes would be extremely difficult to correlate with test data. It was decided to not retain such modes as targets, but to carefully observe the test modes in the event that these eliminated FEM modes are important. 


\section{Sensor Location Analysis}

A number of techniques were investigated for determining accelerometer locations, two of which depended on the larget modes selected (Weighted Average Kinetic Energy and engineering judgment), and (wo others which were independent of the target modes: mass/stiffness ratio method for selecting best master DOF in Guyan Reduction, and a genetic algorithm search method.

Reference to Fig. 6 will be helpful in regard to the following discussions and subsequent sections, for identifying the various structural components of the $X-33$ vehicle. The locations of the liquid oxygen (LOX) and hydrogen (LH2) tanks, aerosurfaces, intertank structure, thrust structure, ballast, aeroshell, and TPS supports (LH2 area) are shown in Fig. 6.

Initially it was reasoned through engineering judgment that the vehicle "hard points" and load paths of the primary structure would make the best candidate sensor locations for measuring global vehicle modes. The X-33 primary structure includes the LOX and LH2 tanks, the intertank structure connecting the tanks, the thrust structure at the rear of the vehicle, and the aerosurfaces. Essentially, this includes most of the vehicle except the TPS and the support structure for TPS. Figure 7 shows the first attempt at a sensor set based solely on engineering judgment. The engine, main and nose landing gear, ballast ring (near nose of vehicle), and areas with relatively large mass concentration (such as batteries) were also selected for measurement points in this initial set. In the following sections the analytical approaches investigated, and results obtained with the techniques, are discussed. It is noted that throughout the process, analytical techniques were combined with engineering judgment to maintain reasonableness and develop a sensor set that could be implemented in the GVT.

\section{Weighted Average Kinetic Energy (WAKE)}

The purpose of using the WAKE method is to obtain the average kinetic energy across a given set of target modes on a DOF-by-DOF basis. Conceptually, the idea is very similar to the modal kinetic energy (MKE) approach for determining target modes, except that $\mathrm{MKE}$ is done on a mode-by-mode basis. Weighted Average Kinetic Energy allows the analyst to find DOF that have the greatest average kinetic energy (or are most active) across the entire set of target modes, and thus are candidate sensor locations for measuring the target modes.

As seen in $\mathrm{Eq}$. (4), the expression for kinetic energy on a DOF basis is quite simple,

$$
[\mathrm{KE}]=\left[\Phi^{\mathrm{T}} \mathbf{M}\right]^{\mathrm{T}} \times[\Phi]
$$

where the symbol $\mathrm{x}$ indicates term-by-term multiplication, and the mode shape and mass matrices have been defined previously for $\mathrm{Eq}$. (3). This expression is related to the classical $1 / 2 \mathrm{mv}^{2}$ relationship for kinetic energy. To obtain the weighted average values across all the target modes, the minimum and average values of kinetic energy for each DOF across all target modes are used:
$[\mathrm{WAKE}]=[\mathrm{KE}] \min [\mathrm{KE}] \mathrm{avg}$

The values are ranked and sorted to determine the candidate set of sensor locations, and the analyst determines how many locations to consider in further analysis.

It was found that the more flexible locations such as the aerosurfaces and outer skin of the vehicle were ranked highest. For analysis in which the top 10,000 DOF, or about 3300 points, were determined, the distribution of highest-ranked points was as follows: (1) acrosurfaces, 1586 points combined; (2) windward skin (aeroshell), 661 points; (3) LOX, 142 points; (4) engine mass simulator, 102 points; (5) thrust structure, 92 points; (6) LOX feedline, 92 points; (7) ballast, 88 points; and (8) avionics bay, 77 points. It is noted that the windward skin was highly ranked because it was modeled as lumped masses attached to the support structure, with the result that some of those DOF were very active. Figures 8 and 9 show the distribution of WAKE points (based on top 3300 locations) for the cutaway view of the model without the outer skin (TPS).

The top 3300 points selected by the WAKE method were used in combination with engineering judgment to obtain a more reasonable number of points for further consideration. For example, the windward skin points were eliminated (since it was known that none or only a few points would be instrumented there), and a generous but much smaller set of aerosurface points was used. A set of about 1300 points was retained at this stage for further analysis. Guyan reduction was performed, retaining the translational $D O F$ at these 1300 points as master DOF. For the empty or no-fuel case, Table 5 shows a comparison of Guyan-reduced model target-mode frequencies (to about $28 \mathrm{~Hz}$ ) in comparison to the full model, along with the Modal Assurance Criteria (MAC) and cross-orthogonality values. In general, the Guyan model based on WAKE results was only accurate for the first few global modes of the vehicle and for "pure" aerosurface modes (clean aerosurface modes, not significantly coupled with other motion).

\section{Diagonal Mass-to-Stiffness Ratio for Guyan Reduction}

The next approach investigated was the mass/stiffness ratio method related to Guyan reduction. This straightforward method involves use of the rules or guidelines for selection of best master (retained) DOF in Guyan reduction. Simply stated, the DOF in the model having the highest diagonal $\mathbf{M} / \mathbf{K}$ values are selected as master DOF, or sensor locations. These DOF having high inertia in comparison to stiffness, when retained as masters or candidate sensor locations, are known to yield Guyanreduced models that usually represent the lowest-order modes quite well.

For analysis in which the top 10,000 DOF (about 3300 points) were retained, as was done for the WAKE method, the distribution of highest-ranked points was as follows: (1) windward skin (aeroshell), 802 points; (2) LH2 tanks, 496 points each; (3) LOX, 263 points; (4) base, 182 points; (5) LH2 frames, 136 points; (6) thrust structure, 128 points; (7) aerosurfaces, 98 points combined; and (8) avionics bay, 96 
points. As was noted for the WAKE results, the windwand skin was highly ranked becausc it was modeled as lumped masses attached to the support structure. Thus, many DOF had relatively high incrtia and low stiffness. Figures 10 and II show the distribution of highest-ranked points for the mass/stiffness ratio mediod.

The number of initially selected points (3300) was modificd and reduced by enginecring judgment to obtain a smaller and more reasonable set (same size as for WAKE) for further evaluation. This was done by (1) eliminating the windward skin points for the reason described previously, (2) eliminating excessive numbers of points for several components, (3) removing points located inside the LOX and LH2 tanks that the method selected, and (4) providing a better distribution of points on the aerosurfaces. As was done for the WAKE method, a set of about 1300 points was retained for further consideration.

Guyan reduction was performed using the translational DOF at the 1300 points. For the empty vehicle case, Table 6 compares the reduced- and full-model (target mode) frequencies, and shows the MAC and cross-orthogonality values, up to $28 \mathrm{~Hz}$. A pattern similar to that observed for the WAKE method is seen, in that the Guyan model based on maximum $\operatorname{diag}(\mathbf{M} / \mathbf{K})$ results was fairly accurate only for the first few global modes of the vehicle and for very clean aerosurface modes. In comparison to Table 5, accuracy for the first few target modes is about the same as for the WAKE method, but overall, the mass/stiffness ratio method did not perform as well as WAKE. This is due to the fact that the mass/stiffness ratio method works well typically only for the lowest order modes, while the WAKE method utilizes the set of target modes of interest to determine the most active points. For the $\mathrm{X}-33$ vehicle, the target modes include not only several low-order modes, but also higherorder modes spread throughout the $0-55 \mathrm{~Hz}$ bandwidth.

Another pattern observed in Tables 5 and 6 is that Guyan reduction appears to lack the accuracy for producing an acceptable test-analysis model (TAM). This perhaps should not be surprising, since Guyan reduction is typically used to obtain reduced models accurate for fundamental or loweronder modes. Accuracy of Guyan models is known to deteriorate for modes higher in the frequency bandwidth.

\section{Engineering Judgment}

Initially, an engineering judgment approach was used independent of the Weighted Average Kinetic Energy (WAKE) and mass/stiffness ratio results. Rather, the $\mathrm{X}-33$ hardware design and the dynamic model were studied to gain insight into possible sensor locations. The following guidelines were used in this effort:

1. Critical load paths of the vehicle and "hard points" were utilized to enhance model verification for loads analysis, and to minimize localized mode effects in the measurements. These areas of the vehicle included the intertank region, thrust structure, LOX and LH2 stiffened regions, and the landing gear.

2. Critical areas for control and flutter were covered extensively: avionics and all aerosurfaces.

3. Initially, the LOX and LH2 frames (TPS support structures) were covered extensively on both the tank- side edges and TPS-side edges. In this manner, TPS (acroshell) effects were accounted for without going directly to the TPS panels, which was found to introduce undesirable localized modes into the retexed model. (A moderate number of points were to be akked later for characterizing TPS dymamics.)

4. All components thought to be of possible interest were covered extensively. These included the ballast, nose, batteries, and others.

The model was basically given good general coverage in the initial engineering judgment set. Vehicle coverage was similar to that shown in Fig. 7, but fewer points were used on the LH2 tanks. Locations on the four main longitudinal stiffeners (top, bottom, and sides) were selected for each LH2 tank (Fig. 6) to reduce the number of points in comparison to Fig. 7 but still capture the motion of interest seen in the target modes.

Approximately 1300 points were obtained by engineering judgment to allow a reasonable comparison with the WAKE and $\mathbf{M} / \mathbf{K}$ ratio results. In Table 7 , results are shown for the empty vehicle case to $28 \mathrm{~Hz}$. As before, Guyan reduced model frequencies are compared to the full model, and MAC and cross-orthogonality values are listed. In comparison to the results in Tables 5 and 6 for the WAKE and $\mathbf{M} / \mathbf{K}$ ratio methods, respectively, the engineering judgment sensor set performed comparably to either method. It performed about the same for the lowest order target modes, much better for the canted fin elevon modes (18.3-18.5 Hz range), and worse for some modes in between.

In a subsequent iteration, the points on the TPS support frames (both LOX and LH2) were removed to observe the effect. The resulting 773-point set showed considerable improvement in MAC and cross-orthogonality values for several modes. This result appears to be due to the presence of hinged fitting mechanisms in the LOX frames, which were designed to accommodate contraction of the tank. For reasons not fully understood, the Guyan reduced model was less accurate when points near the hinges were included.

\section{Engineering Judgment Analysis Combined with WAKE and M/K Results}

Subsequent efforts were focused on reducing and improving the engineering judgment set by incorporating results from the WAKE and $\mathbf{M} / \mathbf{K}$ ratio methods, and also utilizing visual target mode shape inspection. The WAKE method was the primary help in this process. For example, the candidate measurement location set for the canted fins was reduced by plotting the highly-ranked WAKE results on a structure plot of the canted fin model, and using those results as a guide to determine which points in the engineering judgment set to keep or modify. In addition, the bending target modes were visually inspected to observe the locations of peaks or inflection points in the modes. The peaks were seen to match the WAKE rankings to a large degree; highly-ranked points were often on or near a peak in the bending modes.

Results from the WAKE method were also helpful in verifying the selection of LOX measurement points, and both the $\mathbf{M} / \mathbf{K}$ ratio and WAKE results were useful for $\mathrm{LH} 2$ 
points. In some cases, such as the LOX, it was clear that up to half of the 117 points in the first enginecring judgment set could be removed. The critical load paths (stiffened regions of the LOX) were followed in choosing points to retain.

In relation to the thermal protection system (TPS) and its supports, something of a problem was encountered. Based on the design of the TPS support structure, with its hinges and joints for alleviating thermal expansion/contraction, it was expected that uncertainty would be introduced into the test results if the TPS and supports were instrumented. Low shaker forces in modal testing possibly would not free the joints, or nonlinearities would result if some joints were freed and others remained stuck. From this point of view, it would be desirable to avoid instrumenting areas near these joints, and for the candidate set under discussion in this section, sensor points were not chosen on the TPS and supports. However, there was a need to monitor the dynamics of the TPS in the GVT, even though a separate TPS dynamics test was planned. Thus it was realized that the final sensor set should include some points on the TPS supports.

Following the process of combining engineering judgment with WAKE and $M / K$ ratio results, a set of 443 points was determined. Figures 12 and 13 show that this smaller set still defines the shape of the vehicle quite well. Table 8 presents a comparison the the Guyan-reduced model to the full model for the empty vehicle case. Overall, this set performed as well as the 773-point engineering judgment set (original 1300-point set minus TPS support points). The results in Table 8 were considered the best results that had been obtained to that point in the analysis based on engineering judgment, WAKE, and $\mathbf{M} / \mathbf{K}$ ratio results. For this reason, the 443-point set will be used as a reference for further discussions in this section. However, it is noted that this reference set needed to be reduced further because of the sensor count limit of approximately 400 . Additional studies were conducted to reduce the sensor set to 338 points without significant loss in accuracy. This set was well within the limits on number of accelerometers established for the GVT.

To this stage of the analysis, a candidate sensor set had not been evaluated for either of the fueled configurations of the vehicle. To more fully evaluate the reference 443-point sensor set (Figs. 12-13, Table 8), the model for the fullyfueled case was reduced using the Guyan method, retaining the translational DOF at each of the candidate sensor points. In Table 9 the reduced model for this case is compared to the full model up to $28 \mathrm{~Hz}$. Generally, the accuracy achieved for the fully-fueled case is comparable to the empty configuration. However, the MAC worst-case values for three of the modes (modes 6, 16, and 21) were poor.

\section{Advanced Model Reduction Technlques}

Results discussed thus far for Guyan-reduced models of the $X-33$ vehicle have not shown the accuracy expected in comparison to full models for the target modes of interest. Normally, it is desired that the reduced model have target mode frequency errors within about 2 percent, and that the cross-orthogonality diagonal values be approximately 0.95 or greater, with off-diagonals 0.05 or less. Such accuracy of the reduced model is neaded to provide the best opportunity for successfully correlating the model to test data. At this point, it was realized that advanced model reduction lechniques could be required for achieving an accurate test analysis model (TAM). Actually, this is not surprising for the X-33 model, because the target modes are not all lowerorder modes, but are typically scattered through the $0.55 \mathrm{~Hz}$ target mode bandwidth.

One advanced reduction technique that has been used with success is the Improved Reduction System (IRS). This approach is described in detail in Ref. __. To assess the improvement achievable with this approach, the reference 443-point candidate sensor set was used for the empty vehicle configuration. In Table 10, the IRS-reduced model frequencies are compared to the full model, and as before for Guyan reduction, the MAC and cross-orthogonality values are shown. Comparison of IRS results to Table 8 for Guyan reduction to the same DOF set shows (a) significant improvement for target modes up to $17 \mathrm{~Hz}$, (b) accuracy similar to Guyan reduction for the four target modes from $17.8-18.6 \mathrm{~Hz}$, and (c) somewhat worse performance than Guyan reduction for the target modes from $26.9-27.5 \mathrm{~Hz}$. This discussion applies mainly to mode shape comparison; i.e., MAC and cross-orthogonality values. Frequencies obtained with IRS reduction were consistently better through the target bandwidth.

In summary for IRS reduction, it appears that significant improvement in accuracy for both frequencies and modes can be achieved for the lower-order target modes in comparison to Guyan reduction. However, the improvement achieved is still not sufficient to meet the standards for TAM accuracy described previously in this section.

These findings led to consideration of the hybrid reduction method developed by Kammer (Ref. ___). The hybrid approach allows development of a reduced model that is exact for the target modes and frequencies, because the target mode shapes are used in the transformation matrix for the method. In addition, the hybrid technique yields better results for non-target modes than does the modal reduction method (Ref. _ modes.

It was decided to use hybrid model reduction for the final sensor set to achieve the required accuracy for the TAMs. However, Guyan reduction was still used as the criteria for comparing the accuracy of various candidate sensor sets. Hybrid reduction obviously cannot serve as such a comparative criteria because of its characteristics described in the previous paragraph. A possible objection to using hybrid or modal reduction is that a sparse sensor set could yield a very poor static reduction, but obviously also yield an exact hybrid/modal TAM. The implication is that one does not really know the quality of the candidate sensor set. This potential objection is circumvented in this investigation by doing comparative Guyan reductions for all candidate sensor sets to assess their robustness.

\section{Genetic Algorithm Search Technique}

(Analysis and results for this approach will be shown in the full paper.) 


\section{Final Determination of Sensor Set}

As can be seen from the analyses described in this paper, determination of the tinal sensor set was an iterative process. The genctic algorithm search method provided excellent MAC matrices (hased on model partitioning, not model reduction), but the cross-orthogonality values for the Guyanreduced vs. full models were not accurate enough. (Note again that Guyan reduction was used as the measure of comparison for various sensor sets as described in the previous section.) In comparison, the combined engineering judgmen/WAKE/MI/K ratio method produced reasonably accurate orthogonality values for most target modes, as well as fairly accurate MAC values and frequencies in most instances.

The final set of accelerometer locations was a combination of the genetic algorithm optimization results and the engineering judgmenu/WAKE/M/K results. This was done by further reducing the best "combined technique" 338-point set discussed in a previous section and merging it with the genetic algorithm results. Redundancies between the two sets were eliminated, yielding a set of approximately 400 points. This set was referred to as the "final round 1" set. A "final round 2" (and last) set was obtained from round 1 by providing a redistribution of some points selected by the genetic algorithm and the other methods to provide more symmetry and better coverage of the vehicle components. Figure 14 shows the locations of some of the points in the final 405-point set, as well as the distribution (number) of points on each vehicle component.

A number of parameter studies were done relative to the final set, because the Guyan-reduced models were not sufficiently accurate, as was the case for the reference 443point set. Tables 11 and 12 show representative results of these parameter studies for the empty vehicle case. Results in Table 11 revealed that the "round 2" or last set (genetic algorithm points redistributed more symmetrically compared to "round 1") was somewhat better than "round 1". Table 12 shows the effect of removing sensor points on the TPS and LOX feedline on the accuracy of the Guyan reduced model. These locations are highly flexible and/or have joint mechanisms nearby. It can be seen that the MAC and crossorthogonality values improved drastically with these points removed. However, the TPS support and LOX feedline sensor locations are needed to verify TPS dynamics and characterize the feedline for possible "pogo" instabilities. The parameter studies served to provide insight into the poor performace of Guyan reduction for the X-33 model.

Hybrid reduction was used for all three vehicle fuel-level configurations to develop highly accurate TAMs for the final sensor set described in Fig. 14. In all three cases, roducedmodel target frequencies were exact, the diagonal crossorthogonality values were 1.00 , and the off-diagonal values were on the order of $1.0 \mathrm{E}-6$. Figure 15 shows the orthogonality plot for the empty vehicle case.

\section{Shaker Location Analysis}

The final portion of the X-33 pre-test analysis to be described is the determination of adequate shaker locations for the ground vibration test (GVT). Four different approaches were investigated in this effort. As noted previously, the number of shakers for the test was limited to approximately 6 , such that analysis was merited to determine the best locations on the structure and thus save valuable time at the test site.

\section{Weighted Average Drive Point Residue}

The first approach investigated was the weighted avenge drive point residue (WADPR) method. Equation (6) gives the definition of the drive point residue,

$[D P R]=[\Phi] \times[\Phi]\{\Omega\}$

where $\Phi$ and $\Omega$ are the target modes and frequencies squared, respectively, and the symbol $x$ indicates term-by-term multiplication. The weighted average DPR is defined as

$[\mathrm{WADPR}]=[\mathrm{DPR}]_{\min }[\mathrm{DPR}]_{\text {avg }}$

This technique was developed to locate points on the structure that respond most (are most active) across the entire set of target modes. It has been used with considerable success and is available in commercial software packages for pre-test analysis.

Figures 16 and 17 show the highest-ranked WADPR points for the vehicle in the empty configuration. It can be seen that the technique overwhelmingly selected points on the outer parts of aerosurfaces: canted fins and elevons, body flaps, vertical fins and rudders. Obviously, these locations are very active in the target modes. Several points were also selected on the avionics bay and LOX area TPS supports, but none of the points selected were considered attractive for exciting the global target modes of the vehicle.

Locations considered best (engineering judgment and accessibility considerations) for exciting the global target modes were the vehicle "hard points" and load paths, including the thrust structure, forward and aft jacking points, and hoisting points. None of these locations were ranked highly by the WADPR method. In the top 2000 DOF ranked by the method, none of the locations considered most desirable appeared. For the top 20,000 DOF, several desirable hard points were included, but they typically were not ranked highly.

The unsatisfactory results obtained with WADPR led to consideration of other approaches, including a genetic algorithm search technique, engineering judgment (already mentioned in this section), and a frequency response approach combined with engineering judgment.

\section{Genetic Algorithm Search Technique}

(Results and discussion for this technique will be provided in the final paper.) 


\section{Engineering Judgment and Frequency Response Analysis}

The shaker drive locations described in the WADPR section as being desirable for exciting global target modes from an engineering judgment point of view and accessibility considerations are listed below:

1. Thrust structure, hold-down posts (support vehicle on the launch pad)

2. Forward and aft jacking points

3. Forward hoisting points

In reference to Fig. 6 , the forward jacking point is adjacent to (just aft of) the nose landing gear, and the aft jacking points are on the bottom (windward side) of the thrust structure hold-down posts. The forward hoisting points are located to the outsides of the LOX tank, near the nose landing gear station.

These points, along with many other points on the vehicle for comparison, were evaluated using a frequency response approach. This analysis involved a simulation of shaker (or impact hammer) inputs at the DOF selected for evaluation. Frequency response functions (acceleration/force, simulating test data) were computed at the excitation point and at a number of "control" points located literally all over the vehicle. The purpose of this analysis was to determine if the entire vehicle responded to excitation at the candidate shaker points. Computer code was developed to search the response function maxima to locate target mode resonant peaks. The basic concept in this approach is that if most or all target frequencies can be located in the drive-point response or other control point responses for a given excitation DOF, the excitation point is a good shaker location. Comparison of responses for the various candidate shaker locations allows selection of the best excitation points.

Analysis was done for the empty vehicle case to $25 \mathrm{~Hz}$ using the approach described here. Peak searching of the response functions was utilized to find the best excitation location for each direction, and the candidate shaker points were ranked separately for the $\mathrm{X}, \mathrm{Y}$, and $\mathrm{Z}$ drive directions. The best locations for each direction are listed below, in ranked order:

\section{X-direction}

1. Thrust structure, top center

2. Aft jacking, $-Y$ side

3. Forward hoist, $-Y$ side

4. Thrust structure, top right comer $(+Y)$

5. Thrust structure hold-down, $+Y$

\section{Y-direction}

1. Forward hoist, $+Y$

2. Forward hoist, $-Y$

3. Aft jacking, $+Y$ side

4. Thrust structure hold-down, $-Y$

5. Thrust structure, top right corner $(+Y)$
Z-direction

1. Forward jacking

2. Thrust structure, top right comer $(+Y)$

3. Thrust structure, top center

4. Engine, $-Y$ side

5. Aft jacking, $+Y$ side

6. Forward hoist, $-Y$ side

To demonstrate how drive-point response functions compare for good excitation points vs. poor ones, Fig. 18 shows Y-direction drive-point responses for a forward hoisting point (excellent shaker location) and a vertical fin (poor location for global vehicle modes). In the case of the hoisting point, many peaks can be observed, which is a good indication that many target modes are being excited. For the vertical fin, the flexibility of the fin dominates the response, and the other peaks are barely visible. Thus it is difficult to excite Y-direction global target modes with an excitation point on the vertical fin. On the other hand, the fin response function shows how effective driving on the fin would be if the objective was to characterize its dynamics in isolation from the vehicle dynamics.

\section{Final Determination of Shaker Locations}

As was the case for target mode and sensor location selections, the final set of shaker locations was also a combined product of several techniques. The WADPR results verified how active the aerosurfaces are across the set of target modes, and that very active response would occur for drive points on the canted fins and vertical fins. However, a technique utilizing a search of response function peaks showed that global vehicle (bending and torsion) modes would not be well-excited for aerosurface shaker locations, but that driving at the vehicle hard points provided excellent energy distribution in the vehicle.

A final set of shaker locations was the product of all the analysis and engineering judgment. Figure 19 shows the locations on the vehicle for different excitation directions. This set should provide adequate excitation of all global vehicle modes and excitation for verification of aerosurface modes (of interest for flutter and controls).

To evaluate the effectiveness of the sensor and shaker locations for exciting the target modes, extensive numerical simulations were performed. The Multivariate Mode Indicator Function (MMIF) was used to evaluate the effectiveness of the final sensor and shaker set with respect to modal parameter identification. Figure 20 shows the MMIF for the empty vehicle case.

\section{Summary}

Pre-test analysis for the $\mathrm{X}-33$ ground vibration test (GVT) has been described in detail for three configurations: empty, partially-fueled, and fully-fueled. The analytical approaches for determining target modes, sensor locations, and shaker locations were discussed. Although these methods are very powerful and useful, the role of engineering judgment was pivotal for maintaining reasonableness in the results. Knowledge of the vehicle and 
the model was indispensable in the test planning and analysis.

A major conclusion was that Guyan (static) reduction was insufficient for development of accurate test analysis models (TAMs). This was due to the target modes being scaltered through the krget bandwidth, rather than being predominantly lower-order modes. Further, performance of Guyan reduction was degraded by the presence of hinged joints in the LOX TPS support structure, and by the high flexibility of the LOX feedline. It was found that the hybrid reduction technique was required for acceptable accuracy in the TAMs.

Without exception, the target modes, sensor locations, and shaker locations were the products of combined analytical approaches and engineering judgment. No technique when used alone was found to be sufficient for any phase of the pre-test analysis. This is due to the complexity of the X-33 structure and model, with its joint mechanisms and highly flexible aeroshell, and the highly-coupled nature of the mode shapes.

\section{References}

Blelloch, P.A., and Carney, K.S. (1993). Modal Selection in Structural Dynamics, Proceedings of the 11th International Modal Analysis Conference, Kissimee, Florida.

Chung, Y.T (1996). Model Reduction and Model Correlation Using MSC/NASTRAN, MSC/NASTRAN User's Conference, Los Angeles, CA.

Bedrossian, Herand (1998). Optimum Placement of Sensors and Actuators For Modal Identification, Ph.D. thesis, University of Southern California, Los Angeles, CA.

Bedrossian, H. and Masri, S.F. (1999). Optimum Placement of Sensors and Actuators For Modal Identification, Paper to be presented in the Joumal of Sound \& Vibration.

Hidalgo, H. (2000). An Innovative Structural Mode Selection Methodology: Application for the X33 Launch Vehicle FEM, Paper to be presented at the AIAA Dynamics Specialist Conference, Atlanta, GA.

Gawronski, W. K., and Lim, K. B. (1996). Balanced Actuator \& Sensor Placement For Flexible Structures, NASA Tech Brief, Vol.20, No. 6 and JPL report NPO19864.

Glassburn, R.S., and Smith, S.W. (1994). Evaluation of Sensor Placement Algorithms For On-Orbit Identification of Space Platforms, NASA Publication No. 3280.

Holland, J.H. (1975). Adaptation in Natural and Artificial Systems, Ann Arbor,MI.

Juang, J. N., and Pappa, R. S. (1985). An Eigenvalue Realization algorithm for Modal Parameter Identification and Modal Reduction, AIAA J. of Guidance, Control and Dynamics, Vol. 8, No. 5, pp. 620-627.

Kammer, D.C. (1991). Sensor Placement for On_Orbit Modal ldentification and Correlation of Large Space
Structures, Joumal of Guidance, Control, and Dynamics, V14, No. 2, pp. 251-259.

Kammer, D.C. (1992). Effect of Noise on Sensor Placement for On_Orbit Modal Identification of Large Space Structures, ASME Journal of Dynamic Systems, Measurement, and Control, Vol. 114, No. 3, pp. 436-443.

Kammer, D.C. (1992). Effect of Modal Error on Sensor Placement for On_Orbit Modal Identification of Large Space Structures, ASME Journal of Guidance, Control, and Dynamics, Vol. 15, No. 2.

Kammer, D.C., and Triller, M.J. (1992). Efficient Sensor Placement for On-Orbit Modal Identification of Sequentially Assembled Large Space Structures, Proceedings of the 10th International Modal Analysis Conference, San Diego, Ca., pp. 954-964.

Kammer, D.C. (1993). Effects of Noise on Sensor Placement for On-Orbit Modal Identification of Large Space Structures, AIAA/ASME/ASCE/AHS/ASC 34th Structures, Structural Dynamics, and Materials Conference, AIAA-93-1704 CP, pp.3517-3526.

Kammer, D.C. (1993). Sensor Placement for On_Orbit Modal Identification via a Genetic Algorithm, AIAA Journal, Vol. 31, No. 10.

Kammer, D.C., and Brillhart, R.D. (1994). Optimal Sensor Placement for Modal Identification Using SystemRealization Methods, AIAA/ASME/ASCE/AHS/ASC 35th Structures, Structural Dynamics, and Materials Conference, Hilton Head, SC.

Larson, C.B., Zimmerman, D.C., and Marek, E.L. (1994). A Comparison of Modal Test Planning Techniques: Excitation and Sensor Placement Using The NASA 8Bay Truss, International Modal Analysis Conference, Honolulu, Hawaii, pp 205-211.

Larson, C.B., Zimmerman, D.C., and Marek, E.L. (1994). A Comparative Study of Metrics for Modal Pre-Test Sensor and Actuator Selection Using the JPLMPI Testbed Truss, AIAA/ASME/ASCE/AHS/ASC 35th Structures, Structural Dynamics, and Materials Conference, Hilton Head, SC.

Lim, T.W. (1991). Sensor Placement for On-Orbit Modal Testing, AIAAJASME/ASCE /AHS/ASC 32nd Structures, Structural Dynamics, and Materials Conference, Baltimore, MD.

Lim, K.B. (1992). Method for Optimal Actuator and Sensor placement for Large Flexible Structures, AIAA Journal of Guidance, Vol. 15, No 1.

Lim, T.W. (1993). Actuator/Sensor placement for Modal Parameter Identification of Flexible Structures, Intemational Modal Analysis Conference proceedings.

Liu, C. and Tasker, F.A. (1994). Sensor Placement Using Time Domain Perturbation Approach. Proceedings of the AIAA Dynamics Specialists Conference, Hilton Head, S.C., pp. 163-172.

Liu, C., and Tasker, F. A. (1995). Sensor Placement for Multi-Input Multi-Output Dynamic Identification. AIAA-95-1114-CP.

Liu, C. (1995). Optimal Placement Of Sensors For Structural Identification, 
Longman, R. W. and Juang, J. N. (1989). System Identification via Eigensystem Realization, AIAA J. of Guidance, Control, and Dynamics, pp 647-652.

Maghami, P.G. and Joshi, S.M. (1991). Sensor-Actuctor Placement for Flexible Structures with Actuator Dynamics, AIAA-91-2606-CP.

Maghami, P.G., and Joshi, S.M. (1993). Sensor-Actuator Placement for Flexible Structures with Actuator Dynamics, Journal of Guidance, Control, and Dynamics, Vol. 16, No. 2.

Moore, B.C. (1981). Principal Component Analysis in Linear Systems, Controllability, Observability and Modal Reduction, IEEE Trans. Autom. Control, vol. 26.

Norris, G. A., and Skelton, R. E. (1989). Selection of Dynamic Sensors and Actuators in the Control of Linear Systems, Journal of Dynamic Systems, Measurement, and Control, Vol. ill, pp. 389-397.

Panossian, H., Gawronski, W. , and Osman, H. (1998). Balanced Shaker and Sensor Placement For Modal Testing of Large Flexible Structures, Proceedings of the 16th International Modal Analysis Conference, Santa Barbara, CA.

Papadopoulous, M. and Garcia, E. (1998). Sensor Placernent Methodologies for Dynamic Testing, AIAA Journal, Vol. 36, No. 2.

Pape, D. (1994). Selection of Measurement Locations for Experimental Modal Analysis, Proceedings of the 12th Intemational Modal Analysis Conference, Honolulu, HA.

Pappa, R.S. (1988). Some Instrumentation Requirement Issues for the Space Station Structural Characterization Experiment, Presented at the USAF/NASA Workshop on Model Determination for Large Space Systems, Pasadena, CA.

Parker, G., Brown, J. (1982). Kinetic Energy DMAP for Mode Identification, MSC/NASTRAN Users Conference.

Parker, G., Brown, J. (1983). An Application of the Kinetic Energy Calculation as an aid in Mode Identification, The Shock and Vibration Bulletin.

Parker, G., Rose, T., Brown, J. (1990). The Kinetic Energy Calculation as an aid to Instrumentation Location in Modal Testing, MSC World Users Conference, Los Angeles, CA.

Penny, J.E.T., Friswell, M.I., and Garvey, S.D. (1992). The Automatic Choice of Measurement Locations for Dynamic Testing, Proceedings of the 10th Intemational Modal Analysis Conference, San Diego, CA., pp. 30-36.

Salama, M., T. Rose, J. Garba. (1987). Optimal Placement of Excitations and Sensors for Verification of Large Dynamical Systems, 28th SDM conference, pp. 1024-1031.

Salama, M., Bruno, R., Chen, G-S., and Garba, J. (1979). Optimal Placement of Excitations and Sensors by Simulated Annealing. Jet Propulsion Laboratory, Califomia Institute of Technology under Contract with NASA.

Shah, P.C. and Udwadia, F.E. (1978). Methodology for Optimal Sensor Locations for Identification of
Dynamic Systems, Joumal of Applied Mechanics, V45, No 3, pp. 188-196.

Stabb, M. and P. Blelloch. (1995). A Genetic Algorithm for Optimally Selecting Accelerometer Locations, International Modal Analysis Conference, pp. 15301534.

Tasker, F. A. and Liu, C. (1994). Extended Variance Based Techniques for Sensor Location in Modal Identification, Proceedings of the AIAA Dynamics Specialists Conference, pp. 173-181.

Tasker, F. A. and Liu, C. (1994). Variance Based Sensor Placement for Modal Identification of Structures, AIAA J. of Guidance, Vol. 18, No. 3.

Tasker, F. A. and Liu, C. (1996). Actuator and Sensor Placement for Modal Parameter Estimation, AIAA paper No. AIAA-96-1202-CP.

Udwadia, F.E., and Garba, J.A. (1985). Optimal Sensor Locations for Structural Identification, JPL Proceedings of the Workshop on Identification and Control of Flexible Space Structures, JPL Publication 85-29, pp. 247-261.

Udwadia, F. E. (1988). Optimal Sensor Locations for System Identification, Air Force Astronautics Laboratory, Report No. AFAL-TR-87-087.

Yao, L. , Sethares, W.A., and Kammer, D.C. (1993). Sensor Placement for On_Orbit Modal Identification via a Genetic Algorithm, AIAA Journal, Vol. 31, No. 10. 


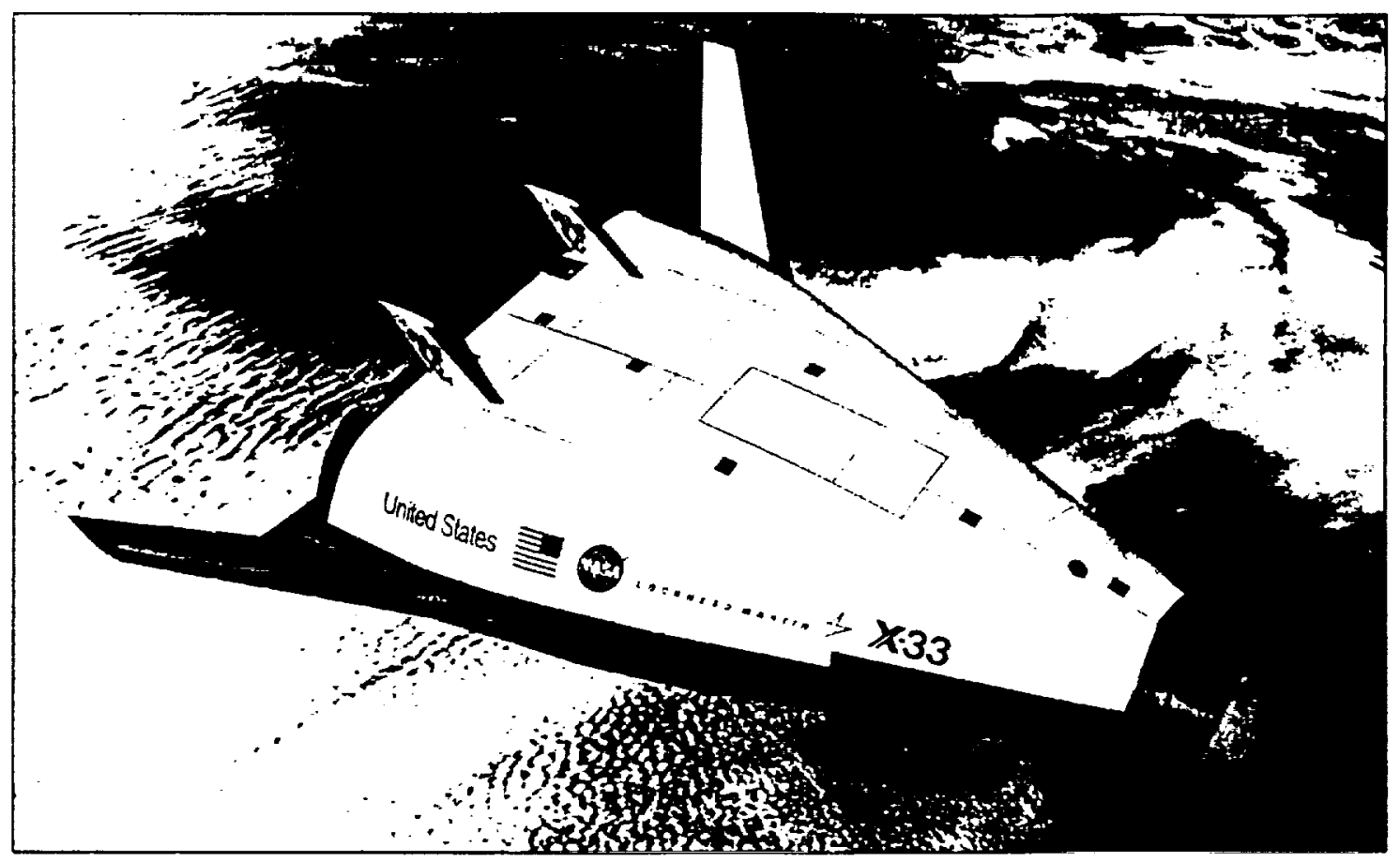

Figure 1. Conceptualization of $X-33$ Vehicle in Flight

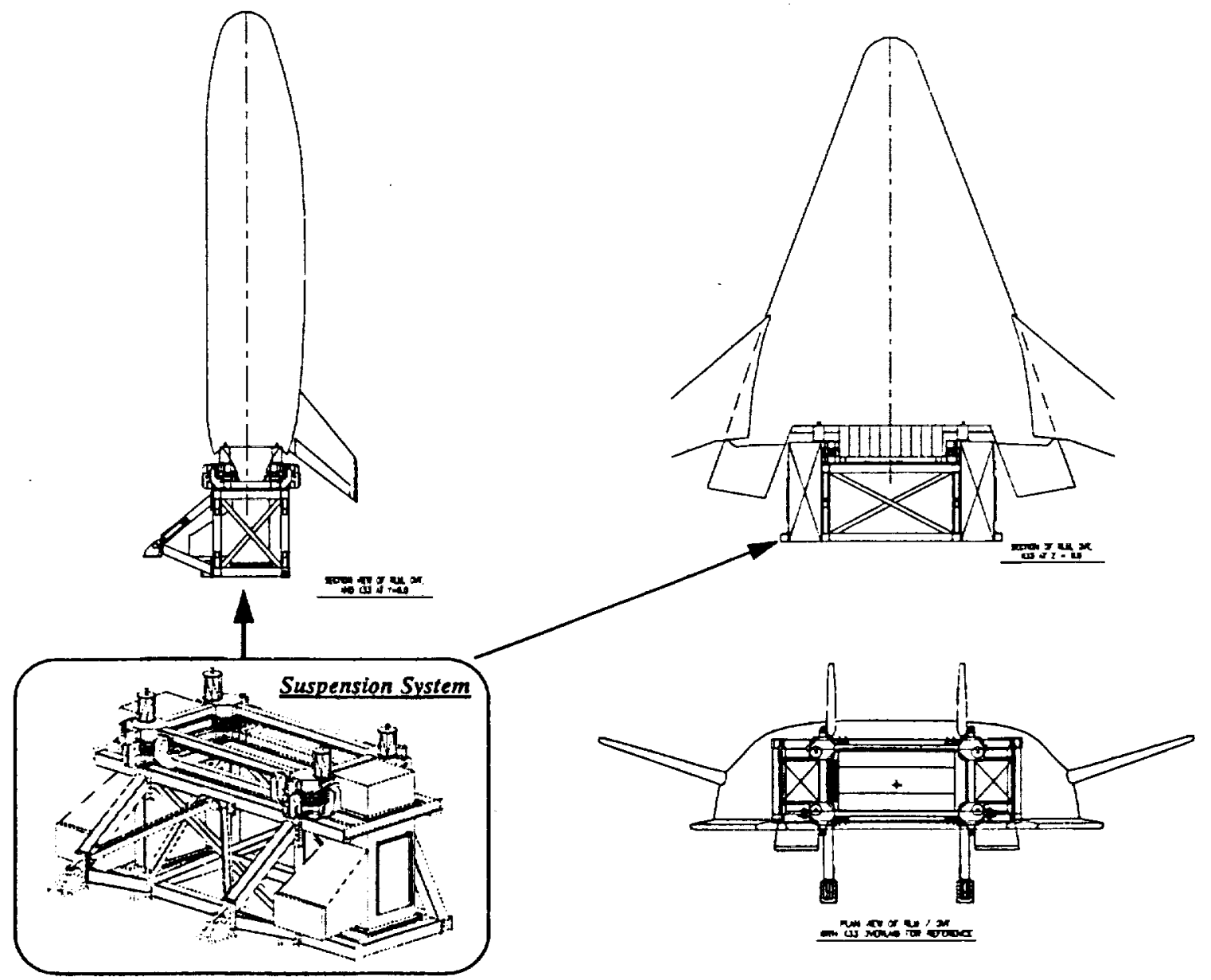

Figure 2. X-33 Vehicle on Suspension System for Ground Vibration Test 


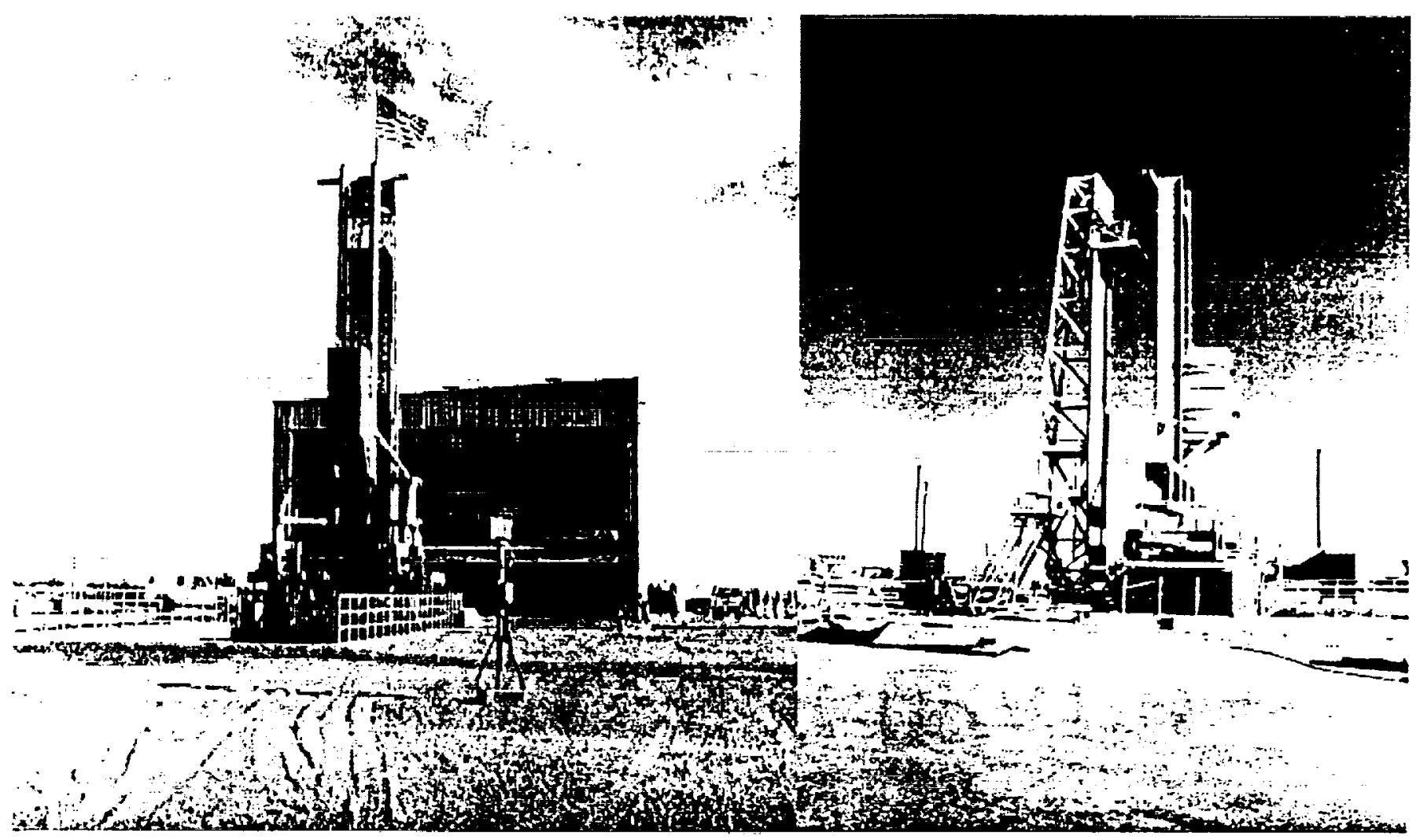

Figure 3. Vehicle Mass Simulator at the Launch Facility

Table 1. Test Objectives and Frequency Ranges for Target Modes

\begin{tabular}{|l|c|c|}
\hline \multicolumn{1}{|c|}{ TEST OBJECTIVE } & Primary Modes & Secondary Modes \\
\hline Vehicle Control & $0-15 \mathrm{~Hz}$. & $15-25 \mathrm{~Hz}$. \\
\hline Flutter \& Aeroelasticity & $0-55 \mathrm{~Hz}$. & - \\
\hline POGO & $0-25 \mathrm{~Hz}$. & $25-35 \mathrm{~Hz}$. \\
\hline Aeroshell Dynamics & $0-100 \mathrm{~Hz}$. & $100-300 \mathrm{~Hz}$. \\
\hline Liftoff Transient Loads & $0-25 \mathrm{~Hz}$. & $25-55 \mathrm{~Hz}$. \\
\hline Vehicle Dynamics & $0-25 \mathrm{~Hz}$. & $25-55 \mathrm{~Hz}$. \\
\hline
\end{tabular}

Number of Target Modes selected per configuration $~ 35$

Total number of modes per vehicle configuration $\sim 950$ 
Table 2. RSS Results for Target Mode Selection, Empty Vehicle
Table 3. Modal Kinetic Energy Results for Target Mode Selection, Empty Vehicle

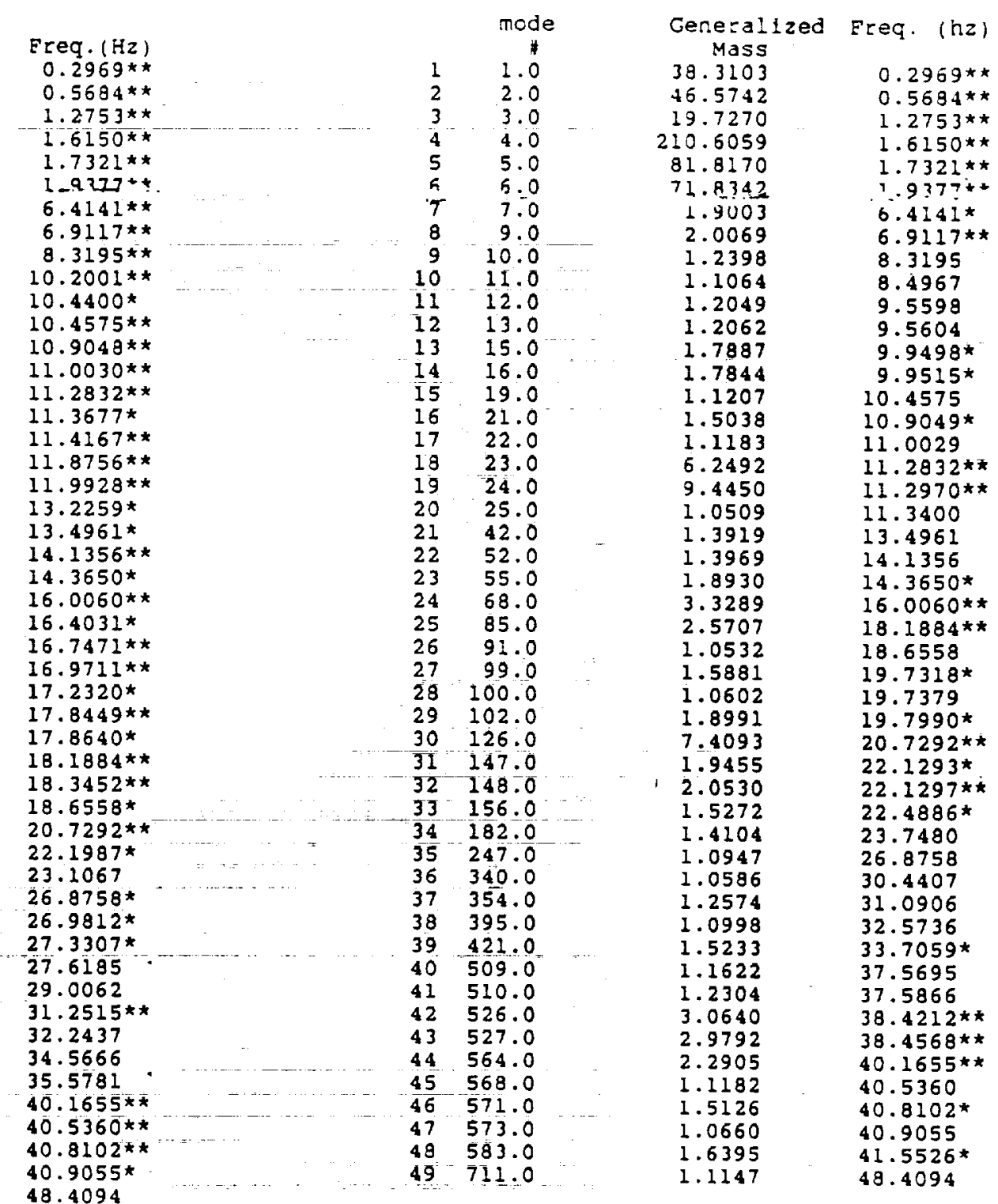




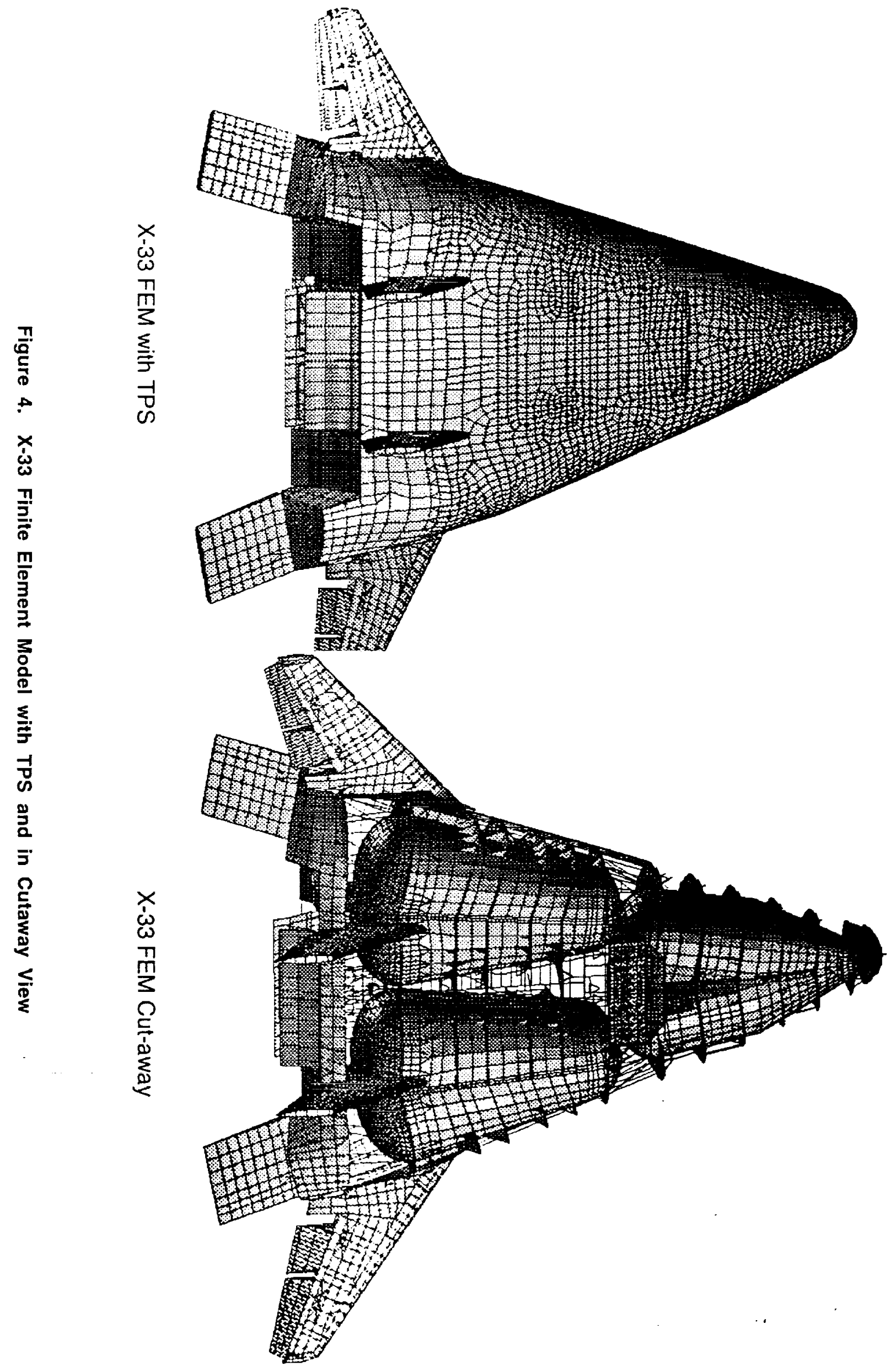




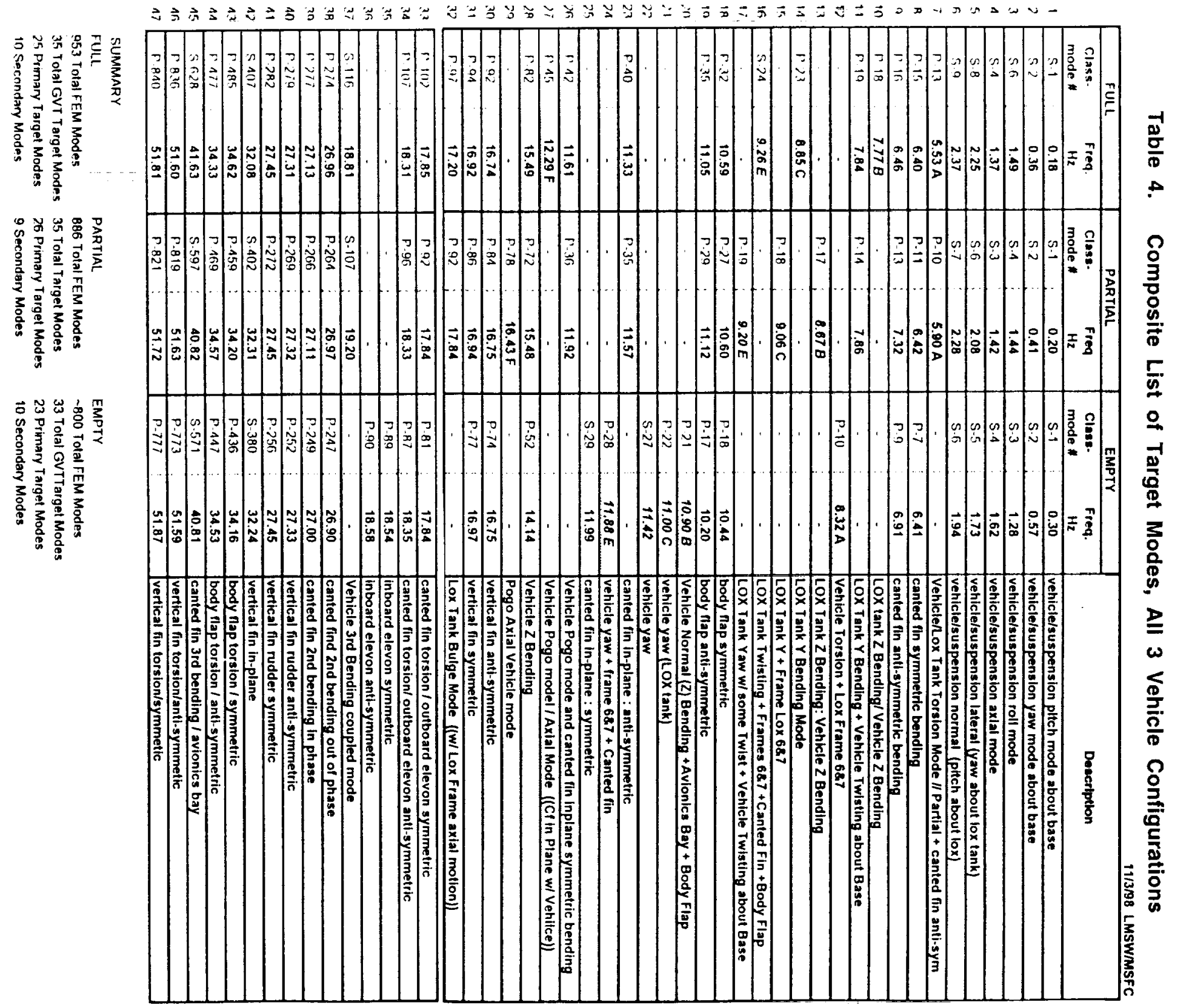



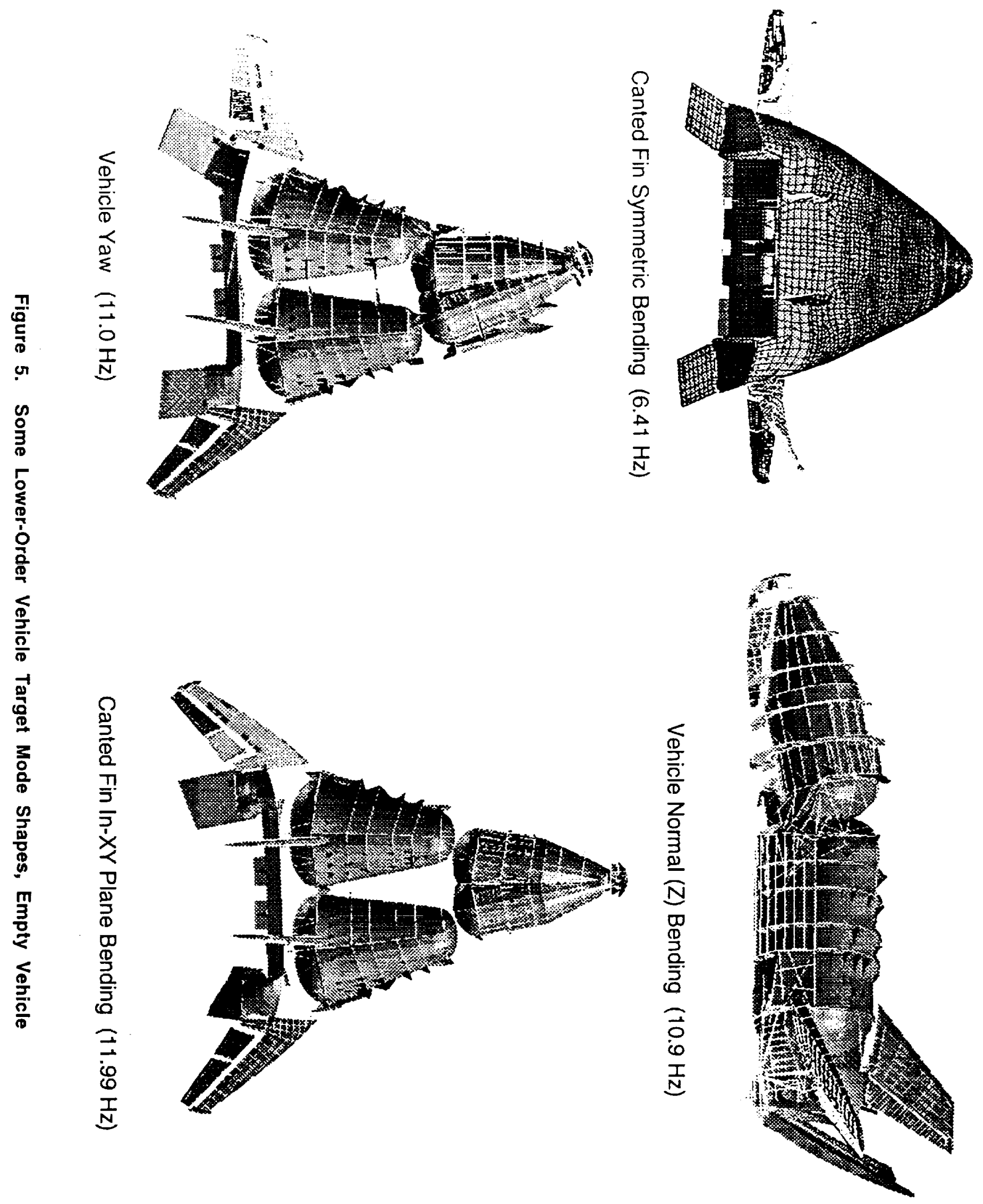


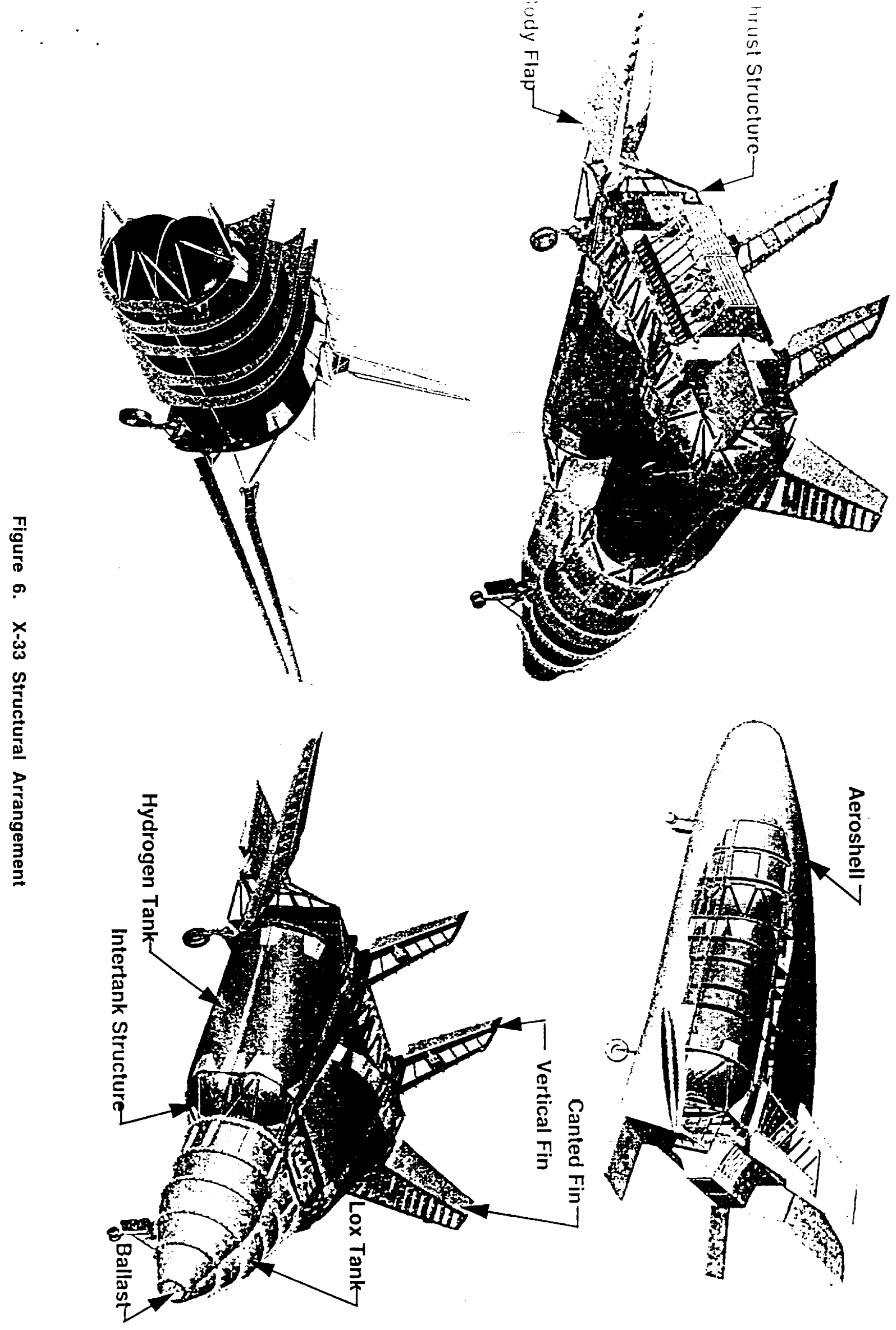




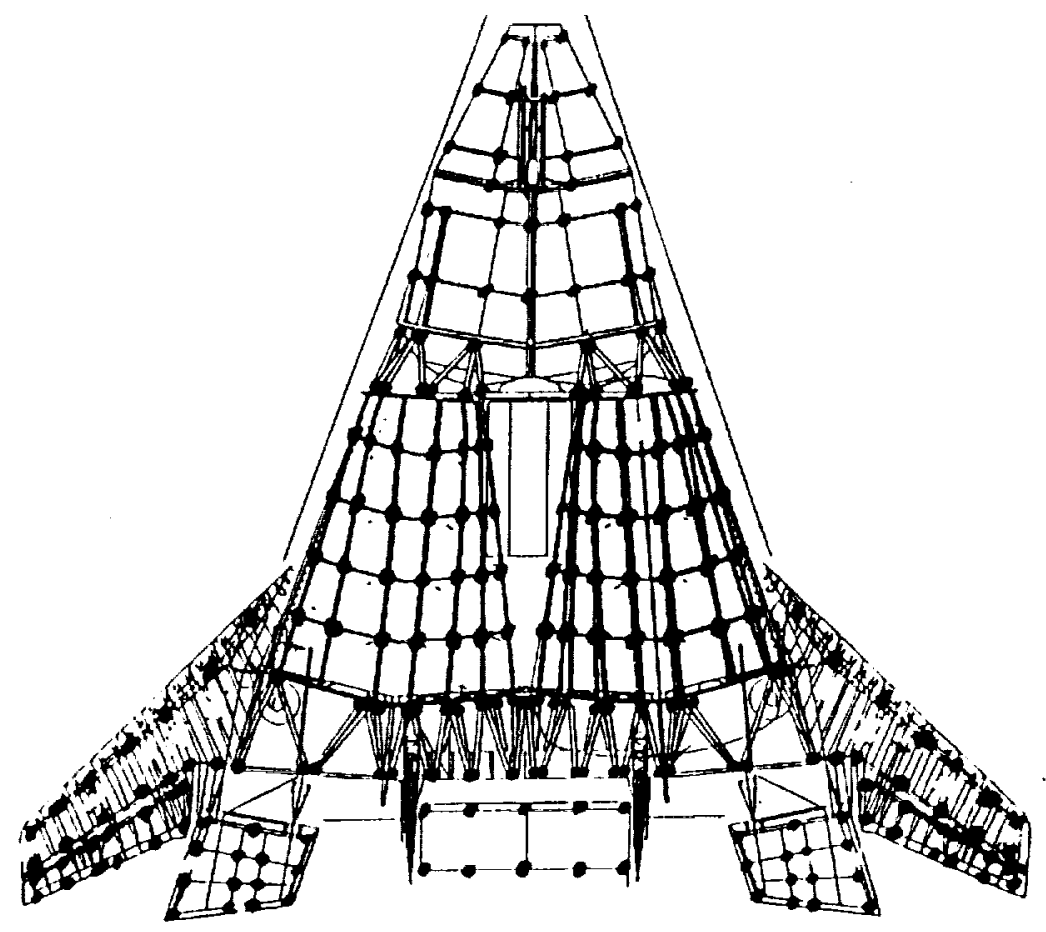

Figure 7. Initial Candidate Sensor Set Based on Engineering Judgment

Table 5. Comparison of Guyan-Reduced and Full Models, WAKE Method (1300 Points, Empty Vehicle)

\begin{tabular}{cccc} 
Full freq. & ASET freq. & MAC & $\frac{\text { XORT }}{.9572}$ \\
\cline { 2 - 3 } 6.41 & 6.43 & .9973 & .9502 \\
6.91 & 6.94 & .9992 & .9602 \\
8.32 & 8.45 & .9993 & .9900 \\
10.20 & 10.12 & .9289 & .7974 \\
10.44 & 10.45 & .4125 & .7211 \\
10.91 & 10.78 & .7809 & .7309 \\
11.00 & 11.09 & .9361 & .9594 \\
11.42 & 11.52 & .8492 & .9290 \\
11.88 & 12.44 & .7410 & .7526 \\
11.99 & 12.00 & .4499 & .7598 \\
14.14 & 14.32 & .5777 & .6789 \\
16.75 & 16.75 & .9944 & .9781 \\
16.97 & 16.99 & .8831 & .8474 \\
17.84 & 17.80 & .8480 & .8735 \\
18.35 & 18.34 & .6535 & .6976 \\
18.54 & 18.55 & .5087 & .7219 \\
18.58 & 18.64 & .7937 & .8920 \\
26.88 & 26.84 & .1477 & .4288 \\
26.98 & 27.14 & .3535 & .3942 \\
27.33 & 27.47 & .6559 & .5702 \\
27.45 & 27.59 & .8970 & .8110
\end{tabular}



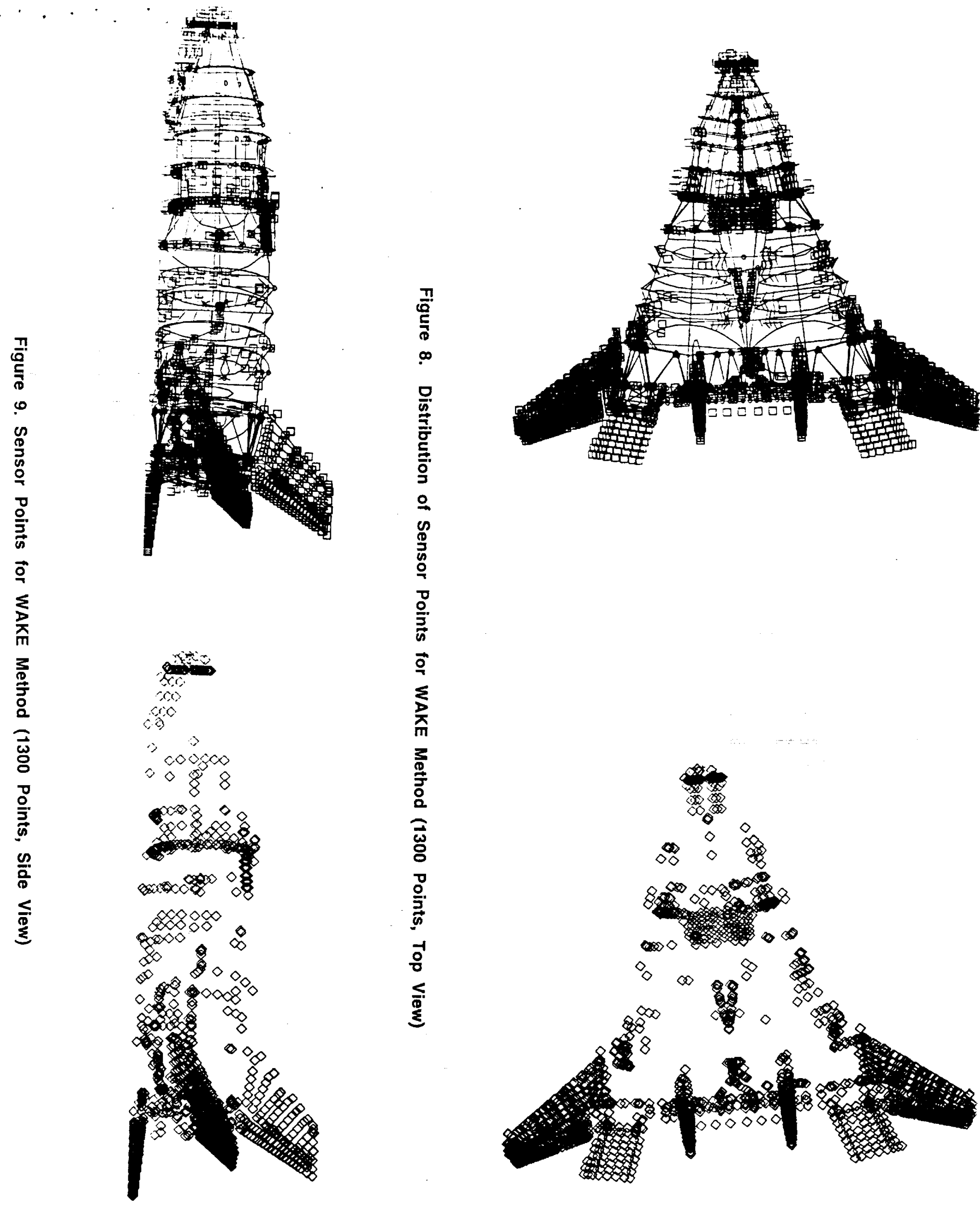

음

$\stackrel{8}{8}$

$\frac{0}{3}$

움

$\sum$

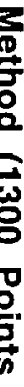

몽

要

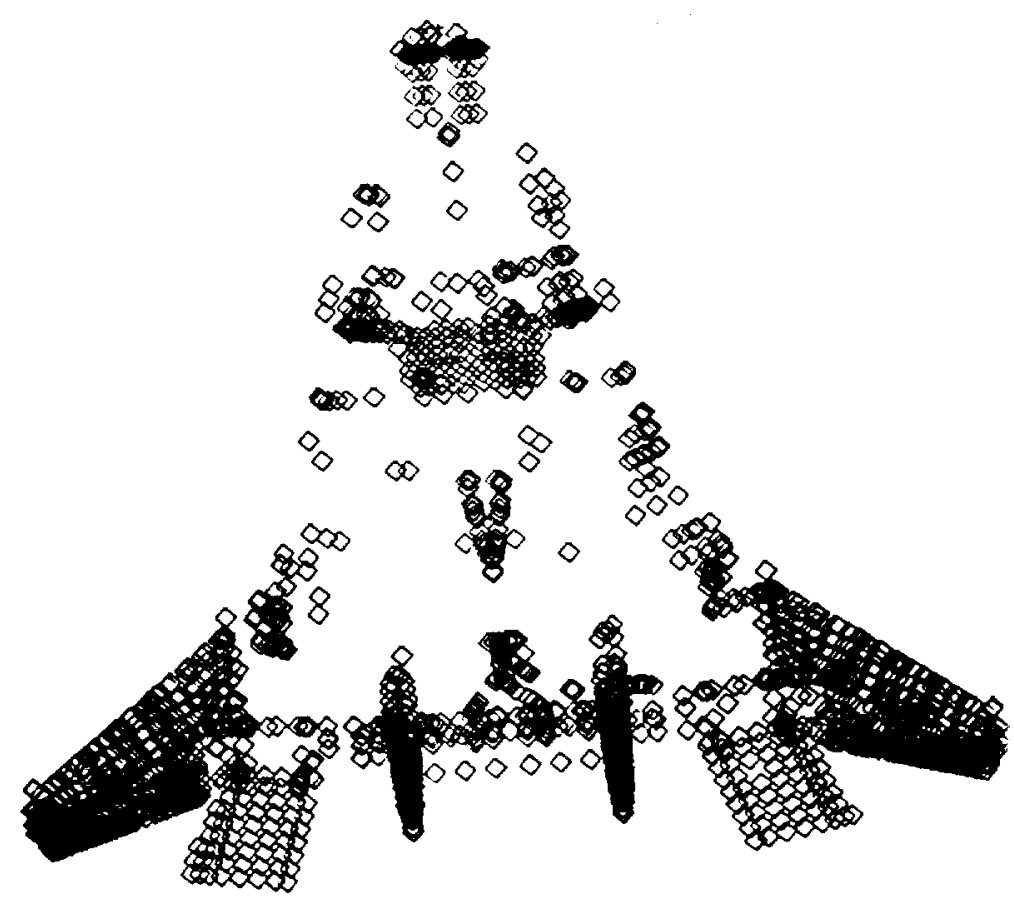



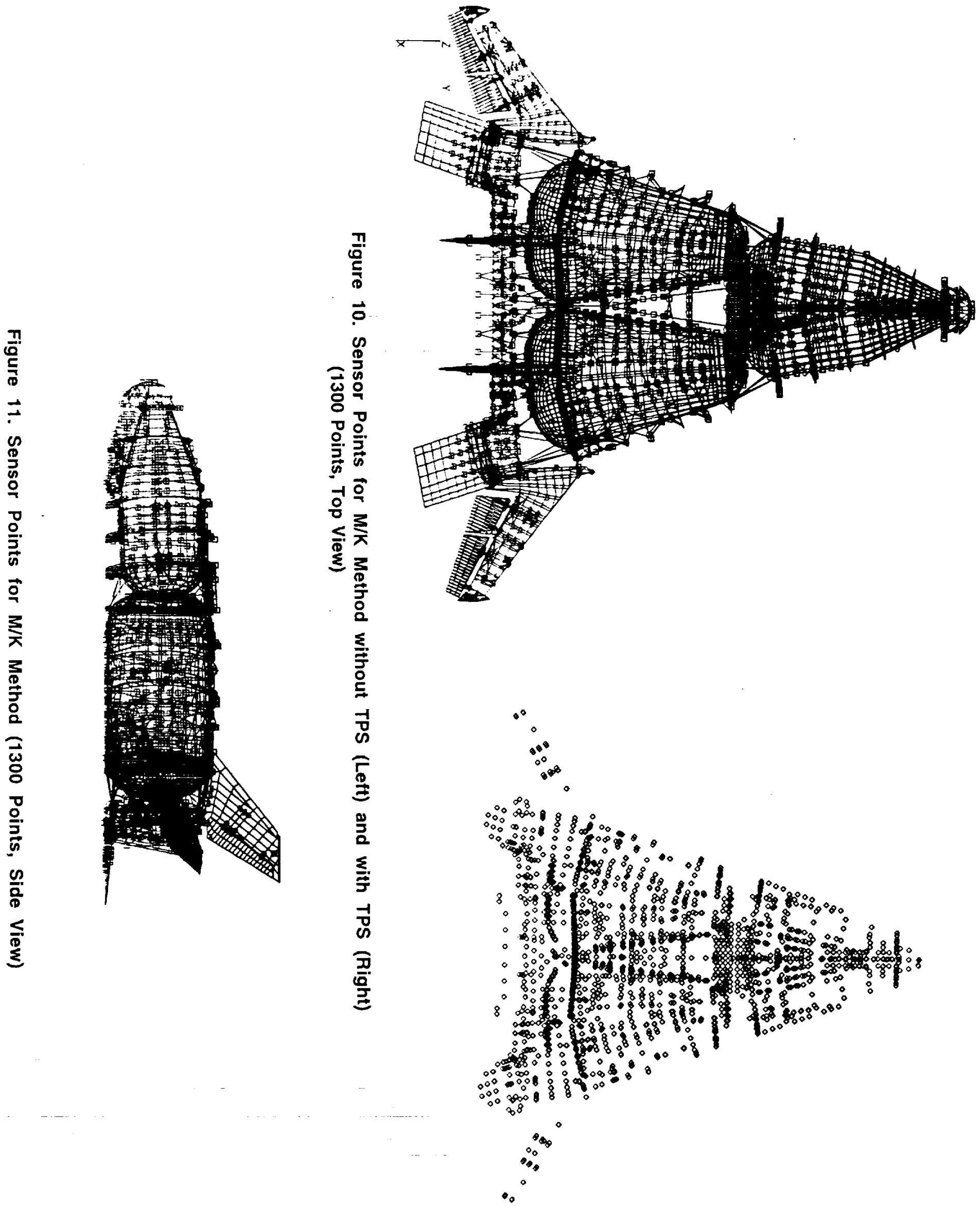
ole 6. Comparison of Guyan-Reduced and Full dels, M/K Method (1300 Points, Empty Vehicle)

\begin{tabular}{|c|c|c|c|}
\hline lull freal. & $\triangle S E T$ freq. & MAC & XORT \\
\hline 6.41 & 6.43 & .9999 & .9961 \\
\hline 6.91 & 6.94 & 9998 & .9607 \\
\hline 8.32 & 8.50 & .9984 & .9934 \\
\hline 10.20 & 10.26 & .9957 & .8808 \\
\hline 10.44 & 10.46 & .5029 & .7712 \\
\hline 10.91 & 11.10 & .8551 & .7489 \\
\hline 11.00 & 11.34 & .7803 & .7381 \\
\hline 11.42 & 11.34 & .7766 & .8138 \\
\hline 11.88 & 12.54 & .7043 & .7722 \\
\hline 11.99 & 12.08 & .7129 & .8179 \\
\hline 14.14 & 14.60 & .4623 & .4099 \\
\hline 16.75 & 16.85 & .9901 & .9627 \\
\hline 16.97 & 17.01 & .7926 & .7127 \\
\hline 17.84 & 18.26 & .4064 & $\begin{array}{l}.6626 \\
7428\end{array}$ \\
\hline 18.35 & 18.93 & .5050 & $\begin{array}{l}.1428 \\
6175\end{array}$ \\
\hline 18.54. & 18.72 & $\begin{array}{l}.3205 \\
3973\end{array}$ & .0110 \\
\hline 18.58 & 18.93 & & .5723 \\
\hline 26.88 & 27.07 & .2149 & .4056 \\
\hline 26.98 & 27.31 & .4137 & .5565 \\
\hline 27.33 & 28.24 & .1904 & .2467 \\
\hline 27.45 & 28.39 & .4688 & .6478 \\
\hline
\end{tabular}

Table 7. Guyan-Reduced versus Full Models, Engineering Judgment (1300 Points, Empty Vehicle)

\begin{tabular}{|c|c|c|c|}
\hline Full freq. & ASET freq. & MAC & XORT \\
\hline 6.41 & 6.42 & .9999 & .9965 \\
\hline 6.91 & 6.91 & .9997 & .9653 \\
\hline 8.32 & 8.47 & .9991 & .9939 \\
\hline 10.20 & 10.32 & .9950 & .9033 \\
\hline 10.44 & 10.58 & .9665 & .8407 \\
\hline 10.91 & 11.08 & .7518 & .8346 \\
\hline 11.00 & 11.14 & .7273 & .8008 \\
\hline 11.42 & 11.84 & .5955 & .7784 \\
\hline 11.88 & 12.69 & .8267 & .7047 \\
\hline 11.99 & 12.07 & .5125 & .8257 \\
\hline 14.14 & 14.68 & .7449 & .7409 \\
\hline 16.75 & 16.86 & .4870 & .5342 \\
\hline 16.97 & 17.10 & .8258 & .8376 \\
\hline $\begin{array}{l}17.84 \\
18.35\end{array}$ & $\begin{array}{l}17.92 \\
18.40\end{array}$ & $\begin{array}{l}.7826 \\
.9657\end{array}$ & $\begin{array}{l}.8632 \\
.9572\end{array}$ \\
\hline 18.54 & 18.58 & .9868 & .9601 \\
\hline 18.58 & 18.65 & .9484 & .9725 \\
\hline 26.88 & 27.05 & .2442 & .3523 \\
\hline 26.98 & 27.24 & .3018 & .4320 \\
\hline 27.33 & 27.49 & .3332 & .3095 \\
\hline 27.45 & 27.61 & .8473 & .8504 \\
\hline
\end{tabular}

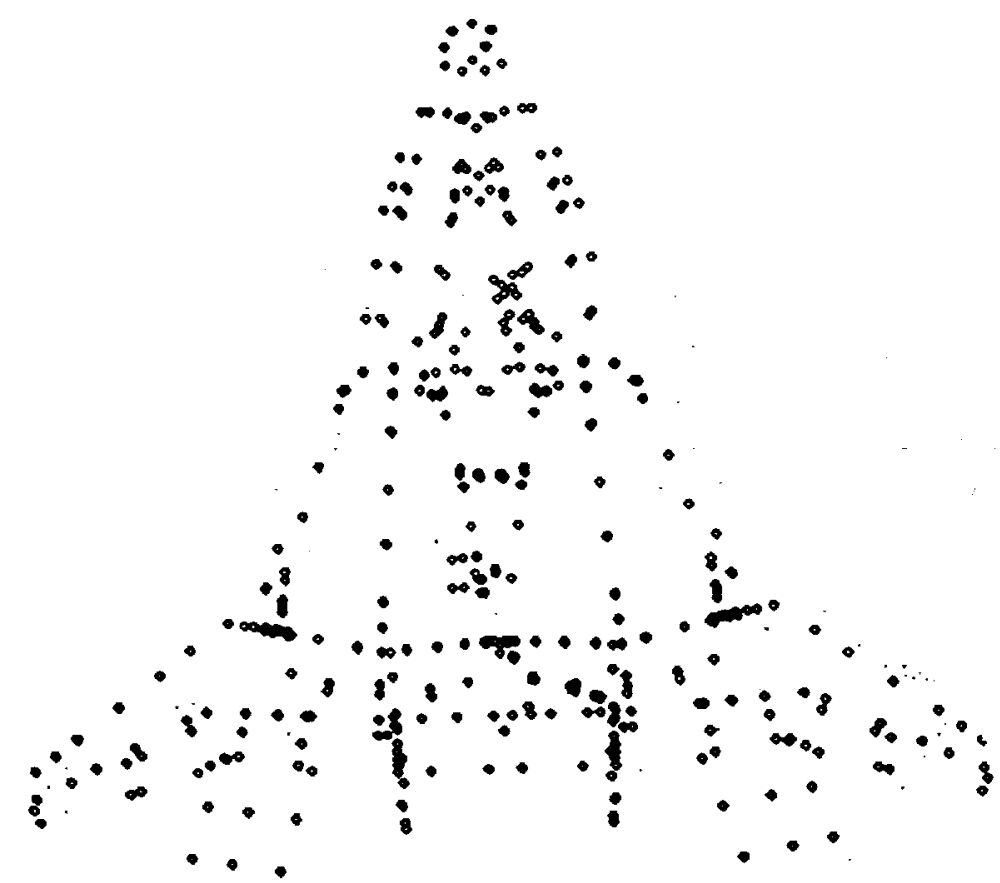

Figure 12. Sensor Points for Combined Engineering Judgment, WAKE, and M/K Methods (443 Points, Top Vlew)
Figure 13. Sensor Points for Combined Methods (443 Points, Slde View) 
Table 8. Comparison of Guyan-Reduced and Full Models, Combined Engineering Judgment, WAKE, $\mathrm{M} / \mathrm{K}$ Methods (443 Points, Empty Vehicle)
Table 9. Comparison of Guyan-Reduced and Fl. Models, Combined Engineering Judgment, WAK M/K Methods (443 Points, Fully-Fueled Vehicle)

\begin{tabular}{|c|c|c|c|c|}
\hline & Full frea & $\frac{\triangle S E T \text { irea }}{642}$ & $\frac{\mathrm{MAC}}{9999}$ & $\frac{\text { XORT }}{9999}$ \\
\hline & $\begin{array}{l}6.41 \\
6.91\end{array}$ & 6.96 & $\begin{array}{l}.9999 \\
.9996\end{array}$ & .9995 \\
\hline & 8.32 & 6.96 & .5704 & .5644 \\
\hline & 10.20 & 10.19 & .9820 & .9862 \\
\hline & 10.44 & 10.57 & .9582 & .9736 \\
\hline & 10.91 & 11.18 & .8762 & .9265 \\
\hline & 11.00 & 11.26 & .8985 & .9052 \\
\hline & 11.42 & 11.26 & .7643 & .8016 \\
\hline & 11.88 & 12.32 & .8691 & .9351 \\
\hline & $\begin{array}{l}11.99 \\
1414\end{array}$ & 12.08 & .9490 & .9740 \\
\hline & $\begin{array}{l}14.14 \\
16.75\end{array}$ & 14.62 & .7085 & .8043 \\
\hline & $\begin{array}{l}16.75 \\
16.97\end{array}$ & 16.77 & .9991 & $\begin{array}{l}.9967 \\
7921\end{array}$ \\
\hline & $\begin{array}{l}16.97 \\
17.84\end{array}$ & 17.11 & .9369 & .7921 \\
\hline & $\begin{array}{l}17.84 \\
18.35\end{array}$ & 18.14 & .8884 & $\begin{array}{l}.9037 \\
8070\end{array}$ \\
\hline & $\begin{array}{l}18.35 \\
18.54\end{array}$ & 18.64 & .7444 & .8970 \\
\hline & $\begin{array}{l}18.54 \\
18.58\end{array}$ & 18.69 & .9829 & .9850 \\
\hline & $\begin{array}{l}18.58 \\
26.88\end{array}$ & 18.77 & .8522 & .8895 \\
\hline & $\begin{array}{l}26.88 \\
26.98\end{array}$ & 27.08 & .7758 & .7608 \\
\hline & $\begin{array}{l}26.98 \\
27.33\end{array}$ & 27.08 & .7066 & .5766 \\
\hline & $\begin{array}{l}27.33 \\
27.45\end{array}$ & 27.64 & .6577 & .6112 \\
\hline Values in & $\begin{array}{l}27.45 \\
32.24\end{array}$ & 27.72 & .9593 & $\begin{array}{l}.9186 \\
6107\end{array}$ \\
\hline italics approximate; & $\begin{array}{l}32.24 \\
34.16\end{array}$ & 32.49 & .5170 & .6107 \\
\hline for $\mathrm{LH} 2 \mathrm{frm}$ pts & $\begin{array}{l}34.16 \\
34.55\end{array}$ & 36.00 & .4464 & .5868 \\
\hline instend of tank hard & $\begin{array}{l}34.55 \\
40.81\end{array}$ & $36.5 I$ & .5694 & .5924 \\
\hline pls. & $\begin{array}{l}40.81 \\
51.59\end{array}$ & 43.36 & .1526 & .3050 \\
\hline & $\begin{array}{l}51.59 \\
51.87\end{array}$ & 52.85 & .6593 & .4775 \\
\hline
\end{tabular}

\begin{tabular}{|c|c|c|c|}
\hline$\frac{\text { Full freq. }}{5 \Omega}$ & $\frac{\text { ASET freq }}{6.14}$ & $\frac{\mathrm{MAC}}{96 / 6}$ & $\frac{\mathrm{XORT}}{8740}$ \\
\hline & $\frac{6.14}{6.41}$ & $\frac{.96 / 6}{.9996}$ & $\frac{.9749}{.9997}$ \\
\hline$\frac{6.50}{6.6}$ & $\frac{6.47}{6.14}$ & $\frac{.776}{.9852}$ & .4871 \\
\hline$\frac{6.6}{020}$ & 7.86 & .9489 & .9907 \\
\hline$\frac{628}{204}$ & 8.44 & -3461 & .6705 \\
\hline$\frac{204}{205}$ & $\frac{8.44}{6.97}$ & .16478 & 8939 \\
\hline 1095 & $\begin{array}{l}6.97 \\
8.44\end{array}$ & 8ces & .8973 \\
\hline 1058 & 10.66 & .9726 & .4824 \\
\hline 11.05 & 11.06 & .9846 & .9790 \\
\hline 11.58 & 71.33 & .9239 & .8891 \\
\hline 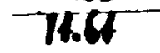 & 71.48 & $.89 / 8$ & .8540 \\
\hline 1219 & 71.48 & .6050 & $.77 / 5$ \\
\hline-15.97 & 15.63 & $.96 / 1$ & .9776 \\
\hline 164 & 16.75 & .9944 & .9658 \\
\hline 16.92 & 17.02 & .9711 & .8726 \\
\hline 17.30 & 19.64 & $-k$ & .6350 \\
\hline 17.96 & $18 / 3$ & .9327 & .9543 \\
\hline $12=1$ & 18.59 & .8058 & .7913 \\
\hline 128 & 19.69 & .6485 & .8365 \\
\hline 26.96 & 2705 & .8884 & .8064 \\
\hline 27.15 & 26.95 & $.2558 \times$ & .4972 \\
\hline $\mathbf{7 7 3 6}$ & 2766 & .7433 & .6300 \\
\hline 24.15 & 27.69 & .9420 & .9259 \\
\hline 3208 & 34.18 & .3395 & .3796 \\
\hline $3 \times 62$ & 36.18 & .3517 & .4724 \\
\hline 3130 & 36.58 & .2377 & .3886 \\
\hline-41.63 & 43.53 & .1772 & .2498 \\
\hline $\begin{array}{l}5600 \\
51.81\end{array}$ & $\frac{52.63}{52.35}$ & $\frac{.6478}{.4525}$ & $\begin{array}{l}.4969 \\
.5706\end{array}$ \\
\hline
\end{tabular}

Table 10. Comparison of IRS-Reduced and Full Models, Combined Engineering Judgment, WAKE, M/K Methods (443 Points, Empty Vehicle)

\begin{tabular}{cccc} 
Full freq. & ASET freq. & $\underline{\text { MAC }}$ & XORT \\
\cline { 2 - 3 } 6.41 & 6.41 & .9999 & .9996 \\
6.91 & 6.91 & .9999 & .9984 \\
8.32 & 8.46 & .9932 & .9386 \\
10.20 & 10.23 & .9970 & .9612 \\
10.44 & 10.47 & .9921 & .9266 \\
10.91 & 10.98 & .9501 & .7214 \\
11.00 & 11.09 & .9868 & .9378 \\
11.42 & 11.51 & .8785 & .8847 \\
11.88 & 12.06 & .8073 & .7444 \\
11.99 & 12.01 & .8569 & .8969 \\
14.14 & 14.15 & .9861 & .8937 \\
16.75 & 16.76 & .9985 & .9816 \\
16.97 & 17.08 & .9942 & .7509
\end{tabular}

$\begin{array}{cccc}\text { Full freq. } & \text { ASET freq. } & \text { MAC } & \frac{\text { XORT }}{17.84} \\ 17.87 & .7964 & .7420 \\ 18.35 & 18.35 & .9771 & .8926 \\ 18.54 & 18.54 & .9786 & .9673 \\ 18.58 & 18.58 & .9499 & .8990 \\ 26.88 & 27.03 & .7647 & .3550 \\ 26.98 & 27.03 & .6723 & .4413 \\ 27.33 & 27.40 & .7547 & .4170 \\ 27.45 & 27.47 & .9667 & .7375 \\ 32.24 & 32.54 & .4999 & .4919 \\ 34.16 & 34.12 & .7251 & .4238 \\ 34.55 & 34.86 & .4605 & .2411 \\ 40.81 & 40.51 & .4689 & .2450 \\ 51.59 & 52.16 & .5723 & .2286 \\ 51.87 & 51.82 & .4412 & .2413\end{array}$


Table 11. Comparison of Final Sets: Round 1 with Original Genetic Algorithm Results, Round 2 with Redistribution of GA Points for Symmetry

Full freq. Guyan freq. Guy.freq. MAC MAC $\underline{\text { XORT }}$ XORT Round 2 Round 1 Round 2 Round 1 $\underline{\text { Round } 2} \underline{\text { Round } 1}$

$6.41 \quad 6.42$

6.916 .93

$8.32 * * 8.50$

$10.20 * * 10.31$

$10.44 \quad 10.48$

$10.91 \quad 11.16$

11.00

11.42

11.88

11.99

14.14

16.75

16.97

17.84

18.35

18.54

18.58

26.88

26.98

27.33

27.45

32.24

34.16

34.55

40.81

51.59

51.87
11.48

$* * 11.48$

$* * 12.58$

12.07

14.97

16.79

17.12

17.96

*18.48

18.67

18.75

*27.10

$-27.10$

27.55

27.76

*33.28

36.22

36.69

*41.09

52.38

52.38
6.42

6.94

8.75

10.38

10.48

11.14

11.46

11.98

I2.65

12.08

14.98

16.79

17.12

17.96

18.41

18.67

18.76

26.82

26.82

27.58

27.72

31.91

35.97

36.80

40.81

52.33
.9999

.9999

**.9914

**.9965

$* * .5448$

*.5140

.5621

*.3563

**.6336

**.6874

.4979

.9920

*.8828

.9371

*.7361

.9906

.9678

**.5638

*.4791

**.4904

**.7694

*.2286

.3505

.1921

.0627

.1438

.2397
.9999

.9987

.6325

.8227

.4368

.6800

.5458

.5768

.4156

.5686

.3423

.9869

.9438

.9424

.8030

.9915

.9837

.4500

.5372

.1377

.1321

.4842

.3331

.1839

.1220

.1348
1.0000

.9999

**.9959

**.9969

**.8082

*.6423

.6706

$* .5165$

**.8025

**.8935

.7803

.9953

*.9136

.9110

**.7576

.9898

.9657

**.6203

**.7026

$* * .5510$

**.7687

**.4562

.5406

*.2661

*.3804

.3927

.3271
1.0000

.9994

.8526

.9221

.7612

.7650

.6581

.7471

.6382

.8587

.7657

.9871

.9413

.9094

.6379

.9897

.9696

.4066

.4174

.4057

.5227

.3710

.5305

.4160

.4757

.3794 
Table 12. Evaluation of Final Sensor Set, with and without TPS and LOX

Feedline Points to Observe Effect on Guyan Reduced Model

\begin{tabular}{|c|c|c|c|c|c|c|}
\hline Full freq & $\frac{\text { Guyan freq. }}{\text { Round } 2}$ & $\frac{\text { Guy. freq }}{\text { No TPS }}$ & $\frac{\text { MAC }}{\text { Round } 2}$ & $\frac{\text { MAC }}{\text { No TPS }}$ & $\underline{\text { XORT }}$ & $\frac{\text { XORT }}{\text { No TPS }}$ \\
\hline 6.41 & 6.42 & 6.42 & 9999 & .9999 & 1.0000 & .9999 \\
\hline 6.91 & 6.93 & 6.96 & 9999 & .9997 & .9999 & .9995 \\
\hline 8.32 & $* * 8.50$ & 6.96 & $* * .9914$ & .6650 & **.9959 & .5678 \\
\hline 10.20 & $* 10.31$ & 10.19 & .9965 & .9830 & .9969 & .9869 \\
\hline 10.44 & $* * 10.48$ & 10.59 & $* .5448$ & .9570 & *.8082 & .9733 \\
\hline 10.91 & 11.16 & 11.22 & *.5140 & .8578 & $* .6423$ & .9367 \\
\hline 11.00 & $* 11.48$ & 11.29 & $* .5621$ & .9641 & $* .6706$ & .9678 \\
\hline 11.42 & $* * 11.48$ & 11.29 & *.3563 & .9337 & $* .5165$ & .9715 \\
\hline 11.88 & $* 12.58$ & 12.34 & $* .6336$ & .8383 & $* .8025$ & .9297 \\
\hline 11.99 & 12.07 & 12.08 & $* .6874$ & .9568 & $* .8935$ & .9772 \\
\hline 14.14 & $* 14.97$ & 14.54 & *.4979 & .7360 & $* .7803$ & .8860 \\
\hline 16.75 & 16.79 & 16.78 & .9920 & .9994 & .9953 & .9992 \\
\hline 16.97 & 17.12 & 17.09 & *.8828 & .9917 & *.9136 & .9706 \\
\hline 17.84 & 17.96 & 17.96 & .9371 & .9688 & .9110 & .9166 \\
\hline 18.35 & 18.48 & 18.48 & $* .7361$ & .8614 & *.7576 & .8363 \\
\hline 18.54 & 18.67 & 18.67 & .9906 & .9885 & .9898 & .9880 \\
\hline 18.58 & 18.75 & 18.76 & .9678 & .9826 & .9657 & .9694 \\
\hline 26.88 & 27.10 & 27.04 & *.5638 & .8890 & $* .6203$ & .8479 \\
\hline 26.98 & 27.10 & 27.04 & $* .4791$ & .9015 & *.7026 & .8320 \\
\hline 27.33 & 27.55 & 27.53 & *.4904 & .7094 & **.5510 & .4921 \\
\hline 27.45 & 27.76 & 27.75 & $* .7694$ & .9074 & $* .7687$ & .8043 \\
\hline 32.24 & *33.28 & 32.89 & $* .2286$ & .5008 & $* .4562$ & .6160 \\
\hline 34.16 & 36.22 & 36.37 & *.3505 & .6485 & $* .5406$ & .6325 \\
\hline 34.53 & 36.69 & 36.67 & $* .1921$ & .6585 & $* .2661$ & .6012 \\
\hline 40.81 & 41.09 & 41.01 & $* .0627$ & .5173 & $* .3804$ & .5967 \\
\hline 51.59 & $* * 52.38$ & 53.40 & $* .1438$ & .4968 & *.3927 & .4992 \\
\hline 51.87 & 52.38 & 52.43 & *.2397 & .7552 & $* .3271$ & .6241 \\
\hline
\end{tabular}




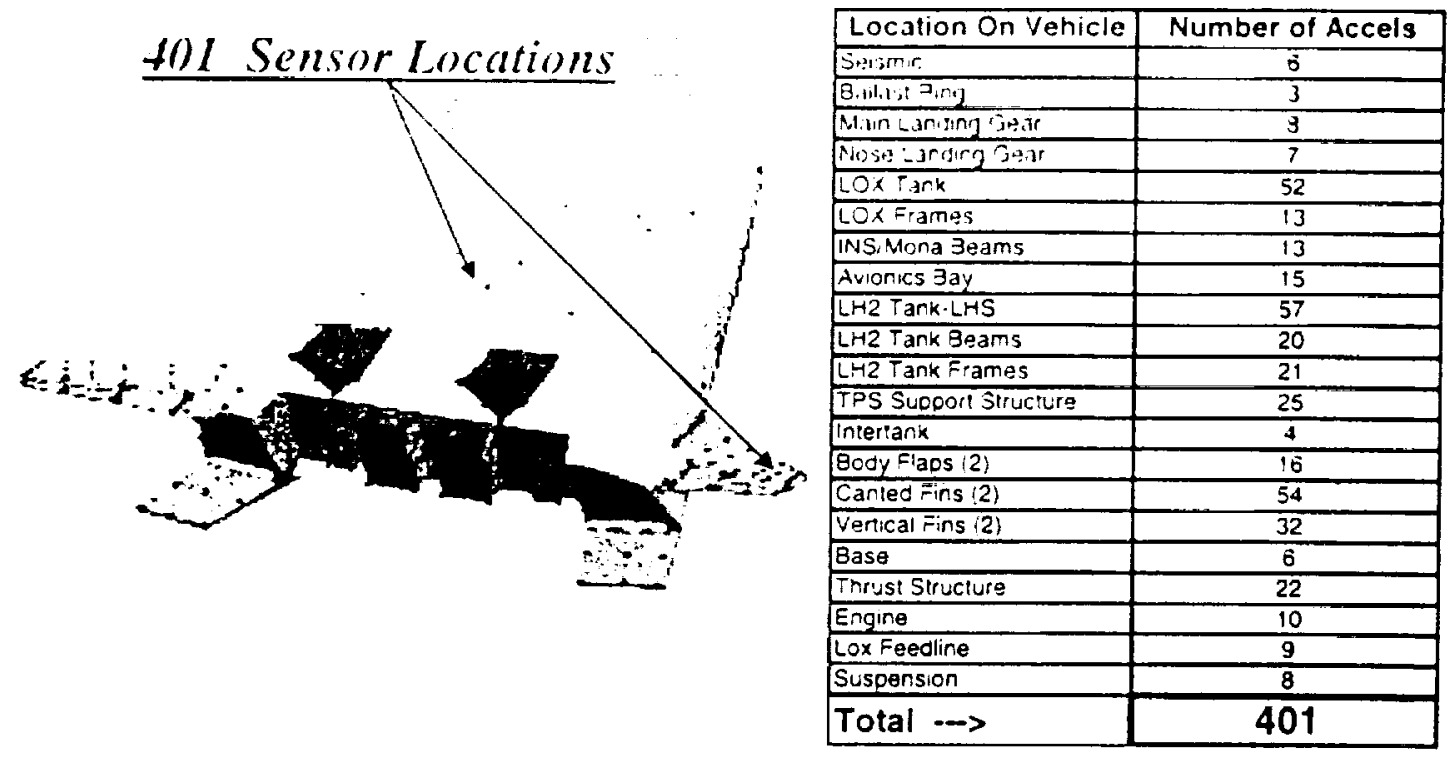

Figure 14. Final Sensor Set Locations and Distribution by Vehicle Component

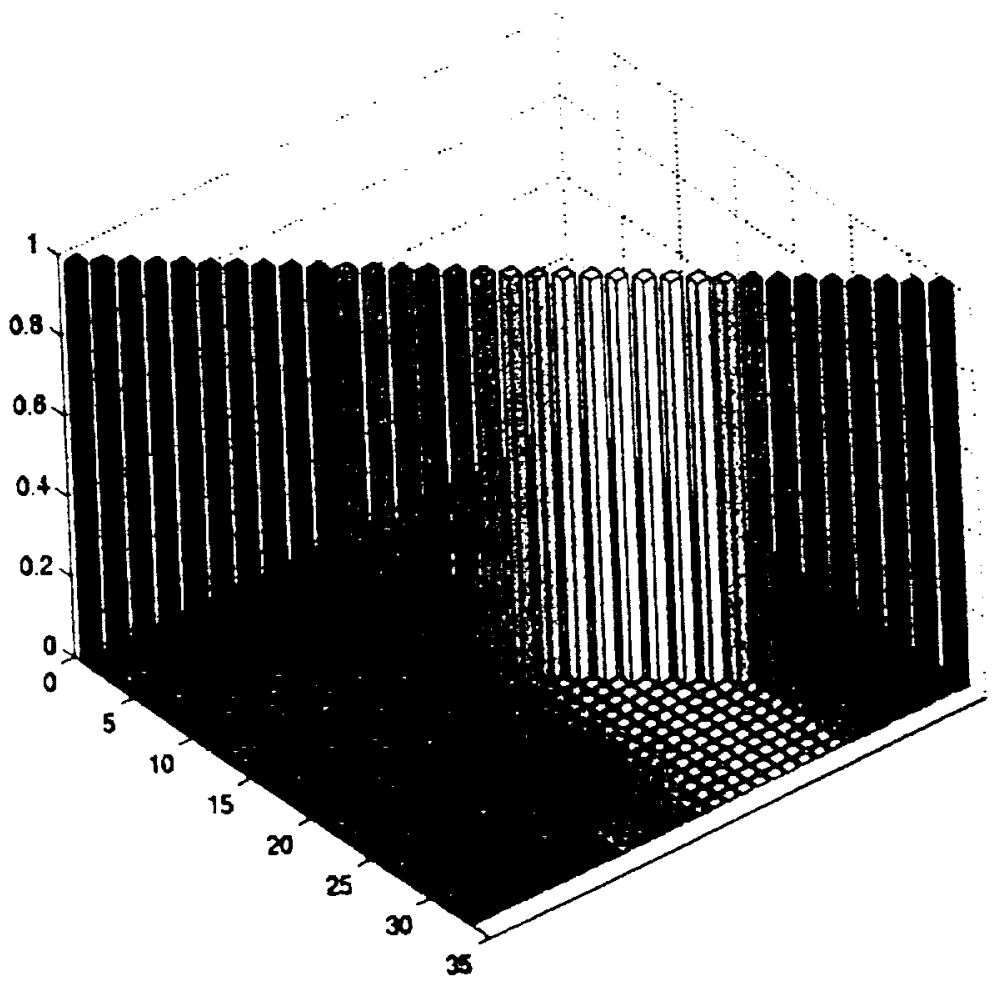

Figure 15. Cross-Orthogonality Plot for Final Sensor Set, Empty Vehicle 


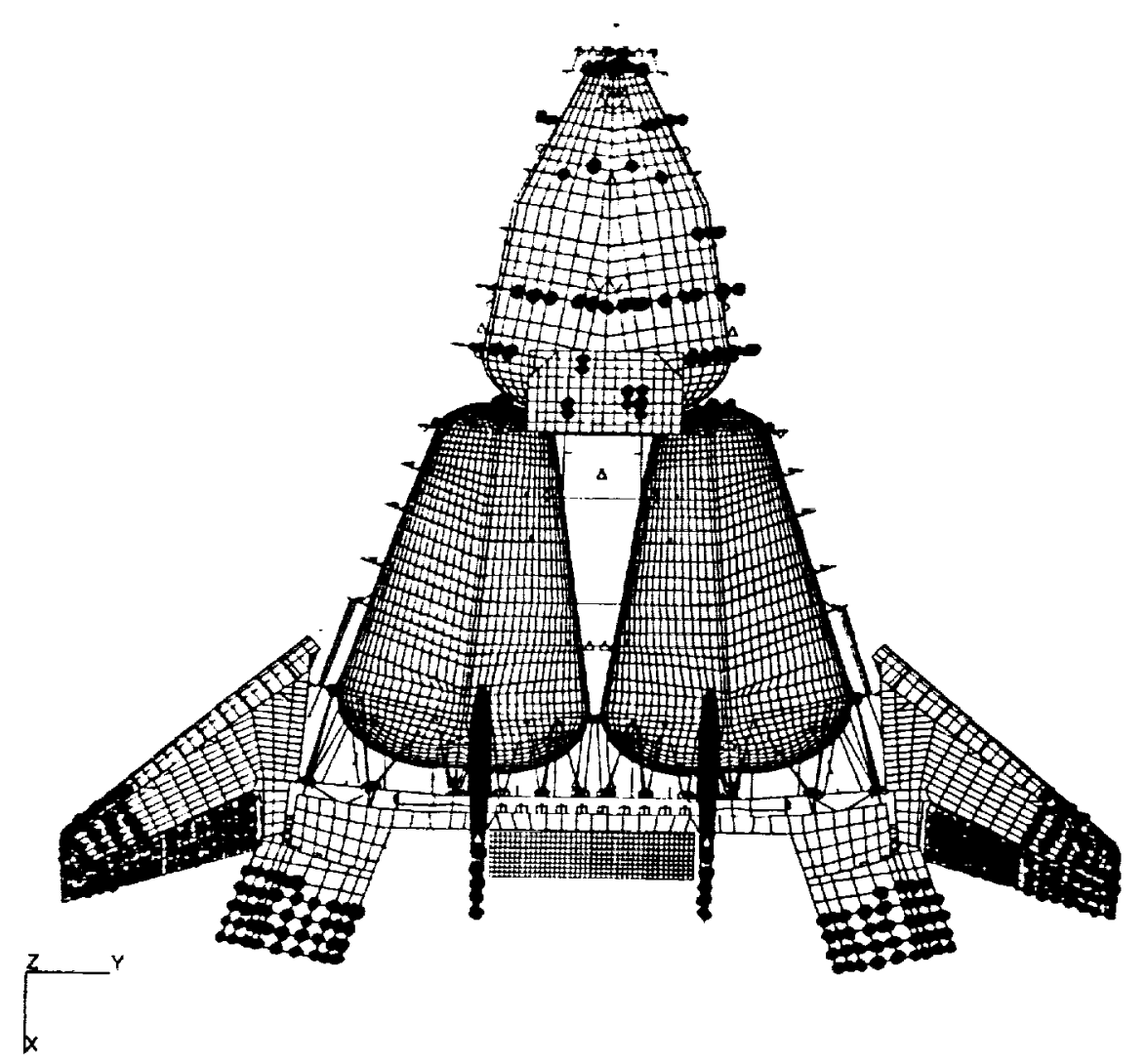

Figure 16. Shaker Locations for WADPR Method (Top View)

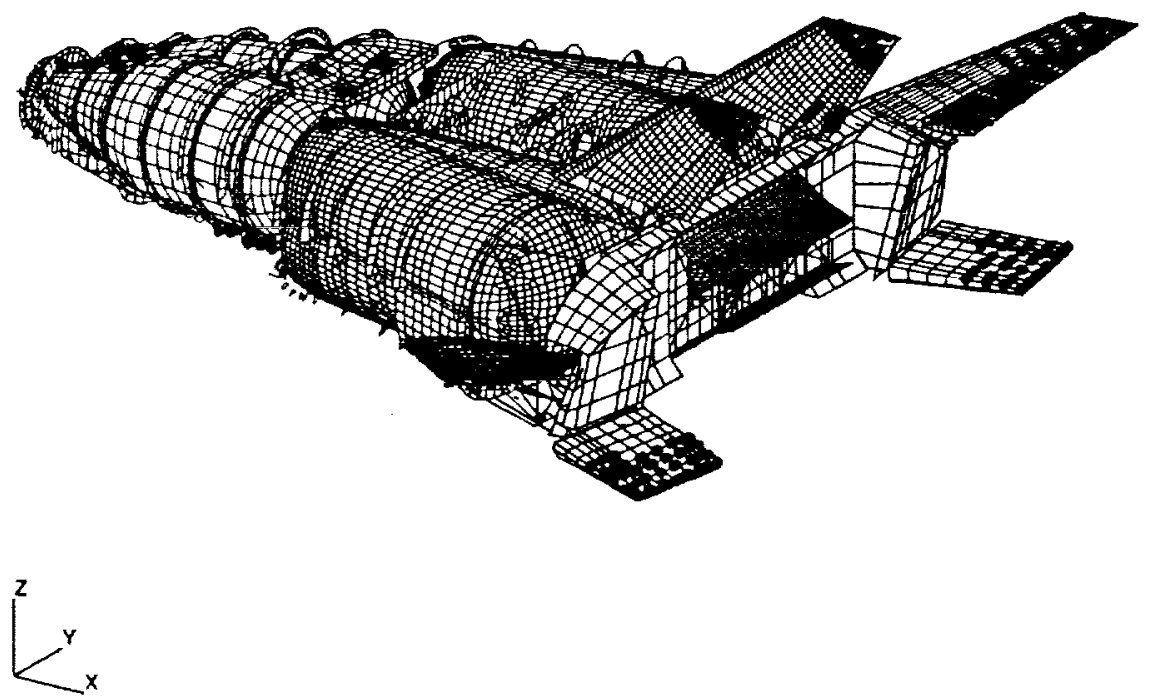

Figure 17. Shaker Locations for WADPR Method (Isometric View) 

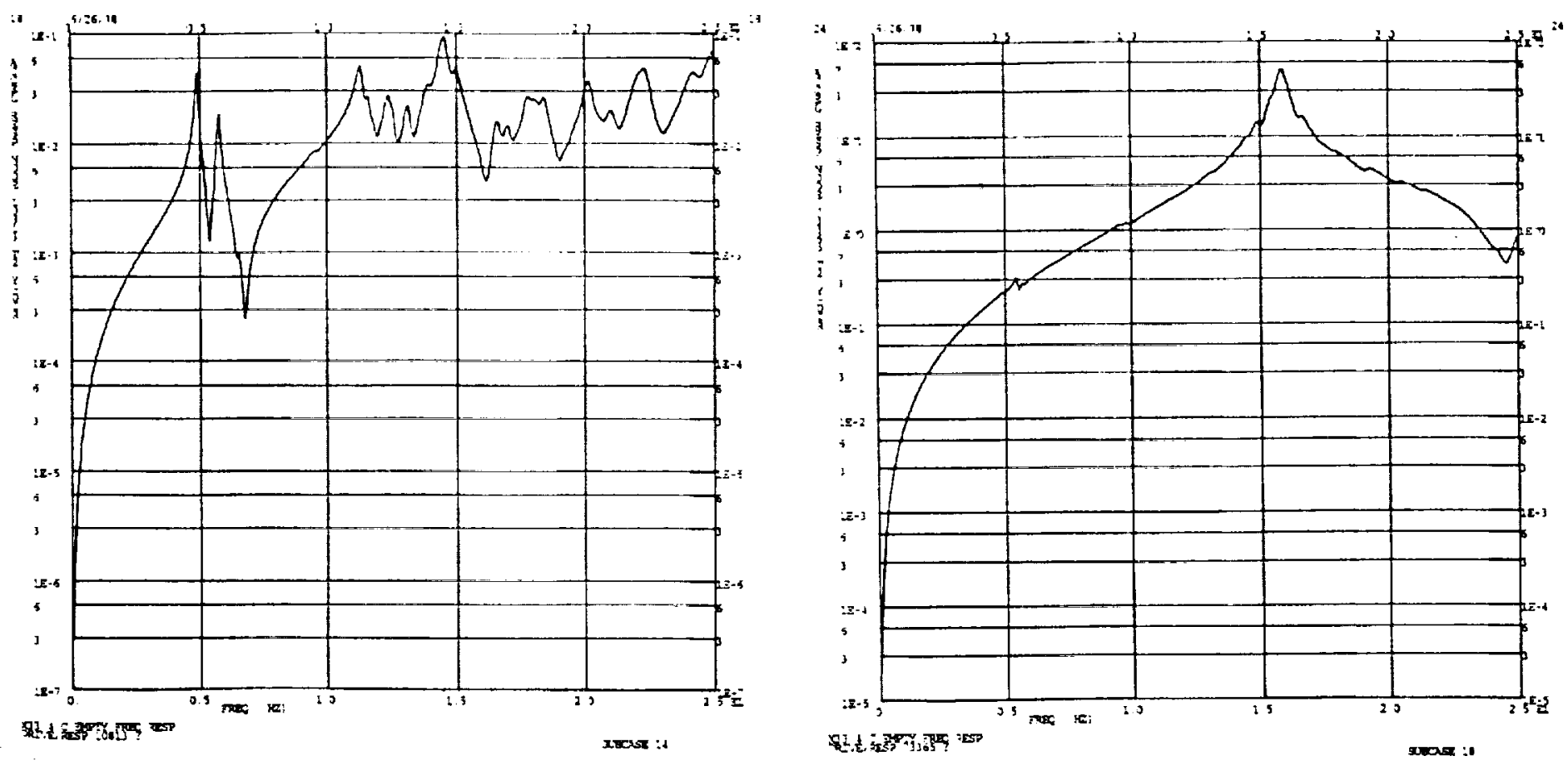

Figure 18. Comparison of Drive-Point Response Functions for Good (Left) and Poor (Right) Shaker Locations for Exciting Global Target Modes

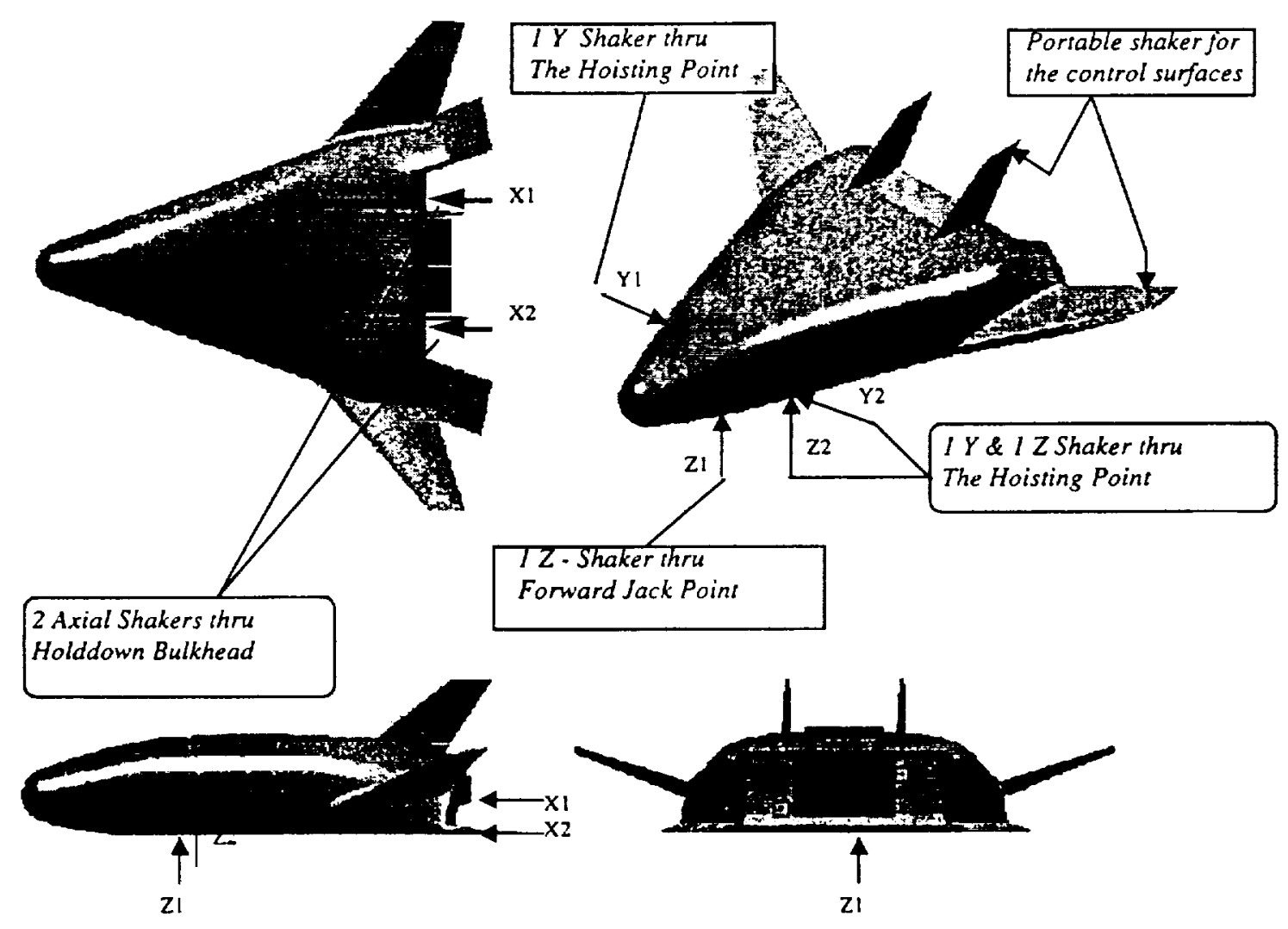

Figure 19. Final Set of Shaker Locations Based on Combination of Techniques 


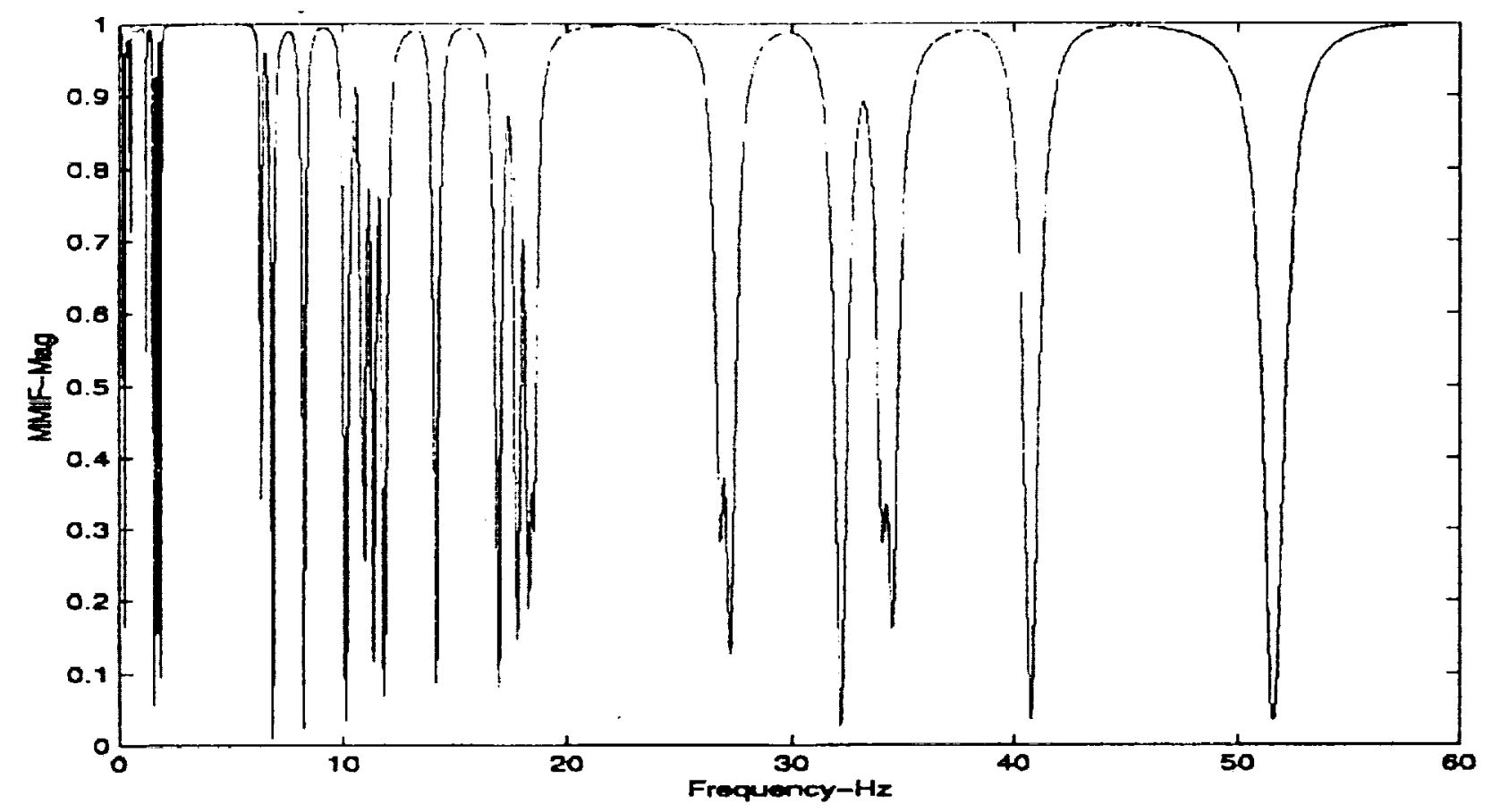

Figure 20. Multivariate Mode Indicator Function for Evaluation of Final Sensor and Shaker Sets 